\title{
اطالة العمر الاستخدامى للزى المدرسى وتحسين جودته "وظيفيا - جماليا"
}

\section{Increase the Consumer Age of School Uniform and Improve its} Quality " Functional-Aesthetical "

\author{
د/ سماح محمد محمد أحمد الصاوي \\ مدرس الملابس الجاهزة بقسم التعليم الصناعي - كلية

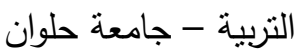

ملخص البحث

مع غياب المعايير المقننة أو المواصفات القياسية لتصميم وإنتاج الزى المدرسى ، إلى إنى

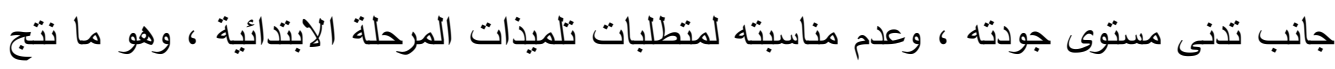

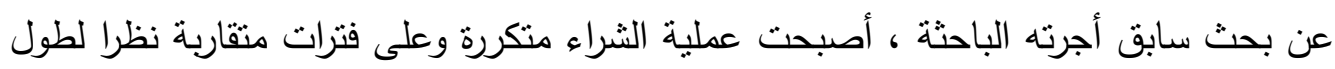
اليوم الدراسي الذي يصل إلى ^ ساعات وفترة الاستخدام التى تبلغ آسنوات. ومع التزايد

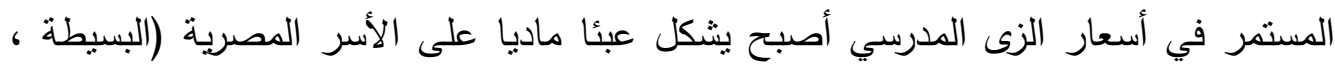
المتوسطة)خاصة إذا تزامن وجود أكثر من طفل أو طفلة بمراحل دراسية متفاوتة داخل الأسرة

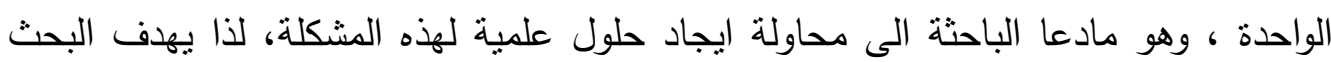

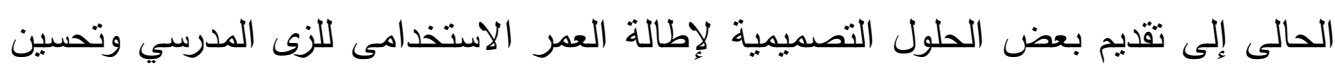
جودته"وظيفيا-جماليا"، الى جانب التعرف على اراء كل من (المتخصصين، المنتجين،الأمهات ،التلميذات) فى هذه التصاميم المقترحة ، ثم إعداد ملف فني لإنتاج التصاميم المثلى والوقوف الته

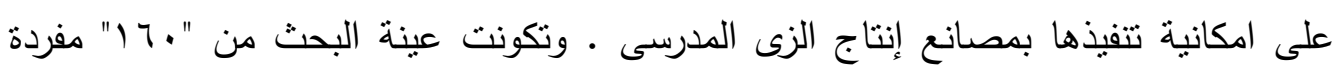

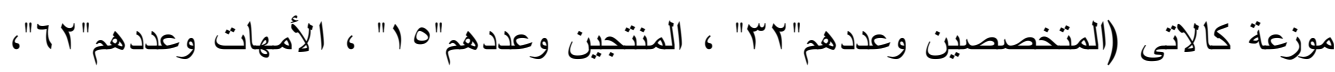

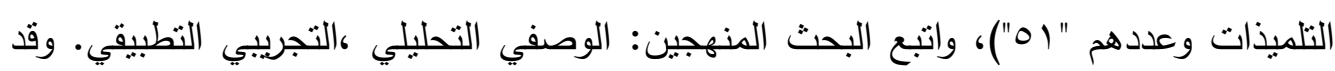
اشتملت أدوات البحث على مجموعة استبيانات لتقييم التصاميم المقترحة من عينات البحث. وتم التحقق من فروض البحث التالية : ا. تحقق التصاميم المقترحة للزى المدرسى درجة قبول ونجاح فئ في ضوء منوسطات تقييم المتخصصين لمحاور التقبيم • r. تحقق التصاميم المقترحة للزى المدرسى درجة قبول ونجاح فى ضوء منوسطات نقييم

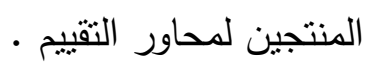


r. تحقق التصاميم المقترحة للزى المدرسى درجة قبول ونجاح فى ضوء متوسطات تقييم

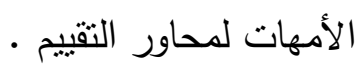

ء. تحقق التصاميم المقترحة للزى المدرسى درجة قبول ونجاح فى ضوء منوسطات نقييم

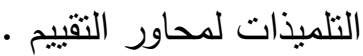

ه. توجد فروق دالة احصائيا بين التصاميم المقترحة للزى المدرسى فى ضوء متوسطات التقييم ككل.

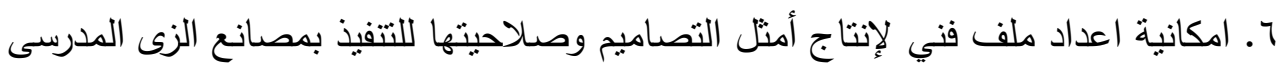
وكانت نتائج البحث كالتالى :

- تقديم حلول تصميمية لإطالة العمر الاستخدامى للزى الددرسي وتحسين جودته وعددها ؛

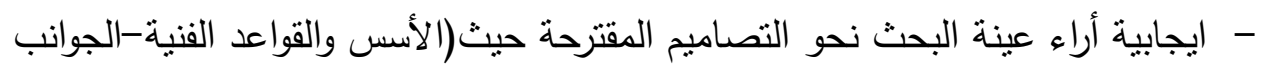
الوظبفية-الجمالية-الاقتصادية)

- أعداد ملف فني لإنتاج التصاميم المنلى الثنلاث شاملا (البناء الهندسي للتصميم المسطح ،

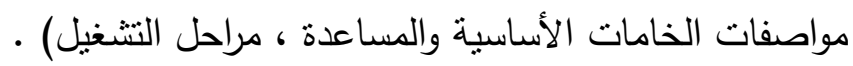

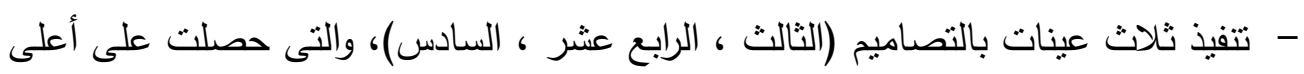

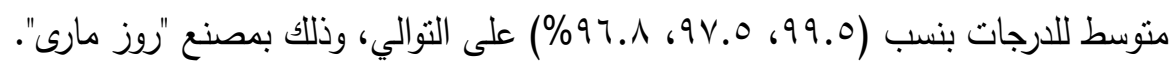

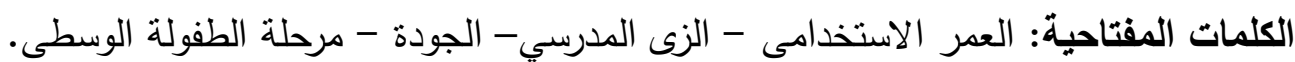

\section{Abstract}

With absence the standard specifications for school uniform s design and production, besides low level of its quality, and unsuitable for girls Requirements in the primary stage which result from previous study to the researcher, that make buying repeated and on nearly times in view of the scholastic day who arrives to 8 hours and use period reach 6 years, and with The continuous increase in prices of school uniform becomes form economical burden on the Egyptian family (simple-middle), especially if found more than boy or girl in disparate stages within the single family. so the current research aims to presenting some designs to increase the consumer age and Improve its Quality (functionalaesthetical), and identify the opinions of(specialists - producers mothers - girls) in these designs, besides preparation technical folder to production the ideal designs and identify usability it implementation in factories of school uniform.and sample consists of a number "160" single distributed as the following (specialists and the number "32" producers and the number "15" - mothers and the number"62"-girls and 
the number"51").and follow the current research analysis descriptive approach, with the application experimental. Moreover, research tools included Questionnaires to Evaluation the Proposed Designs according to Opinions of the Research Samples .

Successfully achieved Research Hypothesis which are the following:

1- the Proposed Designs for school uniform achieve successful and acceptance degree according to Evaluation middle of the specialists.

2- the Proposed Designs for school uniform achieve successful and acceptance degree according to Evaluation middle of the producers.

3- the Proposed Designs for school uniform achieve successful and acceptance degree according to Evaluation middle of the mothers.

4- the Proposed Designs for school uniform achieve successful and acceptance degree according to Evaluation middle of the girls.

5- there are statistical significant different between the Proposed Designs according to Evaluation middle as all .

6- preparation of technical folder for producing the ideal designs and usability to implementation in factories of school uniform.

\section{The Research has the following Results :}

1- presenting some designs to increase the consumer age of school uniform and Improve its Quality (functional - aesthetical) and fourteen the number.

2- find samples positive views about the proposed designs to actualizing (the principles and technical rules - functional - aesthetical - economical sides)

3- preparation of technical folder for production the three ideal designs.

4- implementation three uniforms "drills" with designs (third, fourteen , sixth) that received the highest average scores by ratio $(99.5,97.5$, 96.8\%)

Keywords: consumer age - school uniform - Quality - the middle childhood 


\section{Introduction and Problem : المقدمة ومشكلة البحث}

فى عالمنا المعاصر يقضى الطفل الثطر الهام من حياته فى أجواء المدرسة التى :هى

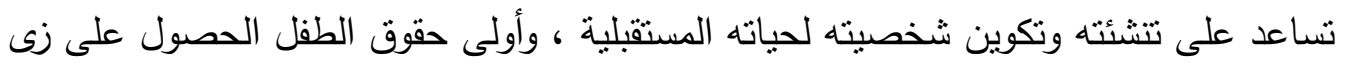
مدرسي يلبى احتباجاته ويفي بمنطلباته،فلم يعد الزى شيئا ثانويا بل أصبح من الأمور الحيوية

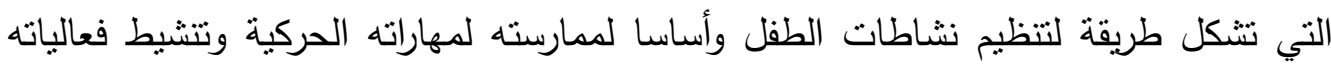

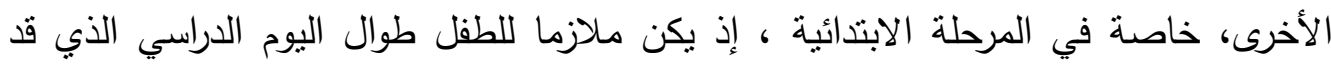

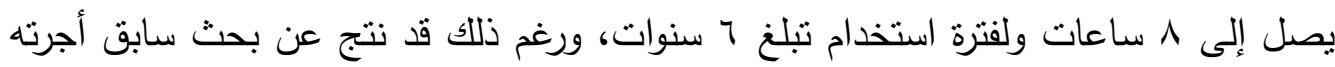
الباحثة في المدارس الابتدائية الحكومية بمحافظات "القاهرة- الجيزة-القليوبية" عدم وجود معايير مقننة أو مواصفات قياسية لتصميم وإنتاج الزى المدرسى،إلى جانب القصور في جودة الزى الزئ التيه

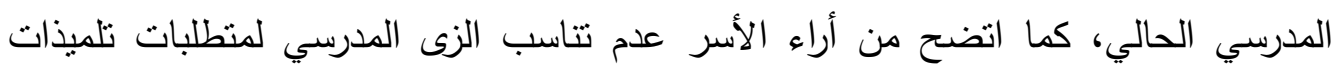

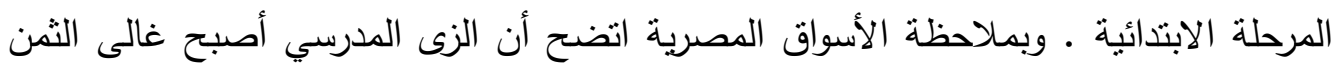

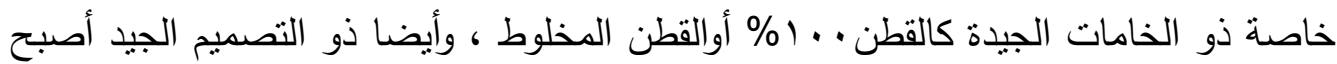

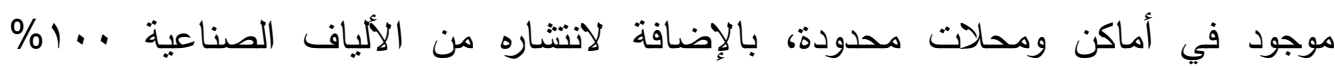

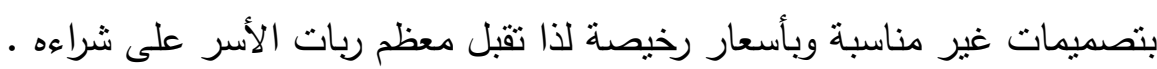
ومع تدنى مسنوى جودة الزى المدرسي ، وعدم مناسبته لمنطلبات تلميذات المرحلة الابندائية، أصبحت عملية الثراء متكررة وعلى فترات منقاربة، ومع التزايد المستمر في أسعاره

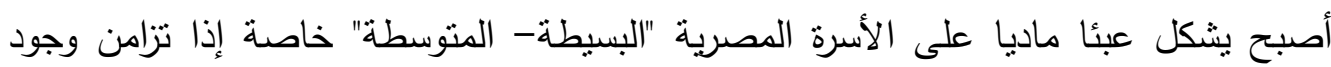

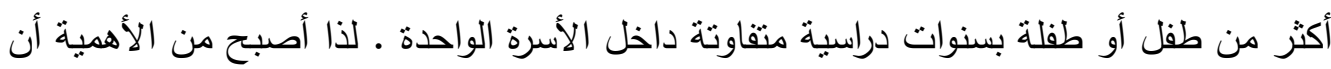
يتولى دراسة الزى المدرسي متخصصون يجمعون بين البراعة في الجوانب الفنية للتصميم

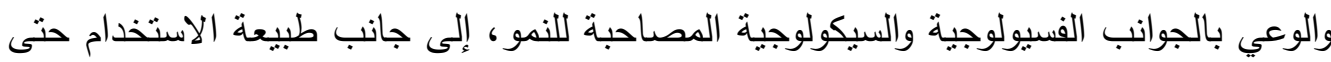

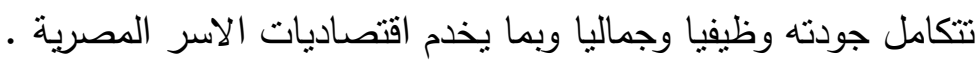

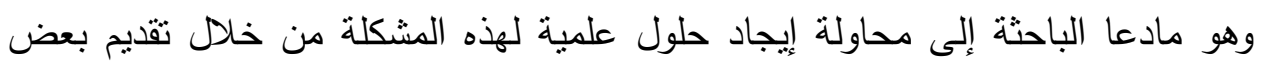
المعالجات التصميمية في محاولة لإطالة فترة استخدام الزى المدرسي الواحد بما يفي بمتطلبات

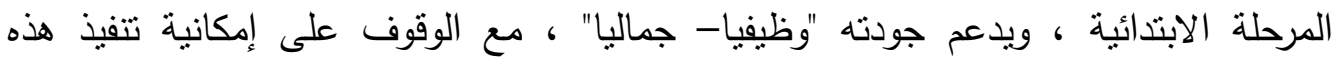

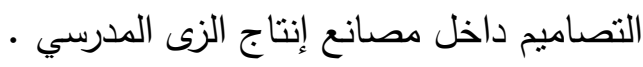


وعن الدراسات والبحوث السابقة فقد وجد البعض الذي تتاول الزى الددرسي من زوايا

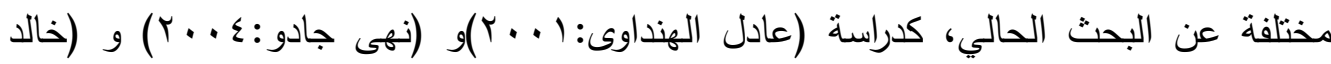

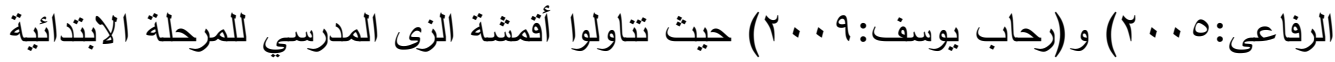

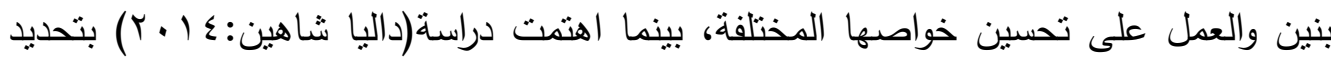
المتطلبات (السيكولوجية- الفسيولوجية- السسيولوجية) لتصميم الزيى المدرسي لطالبات المرحلة

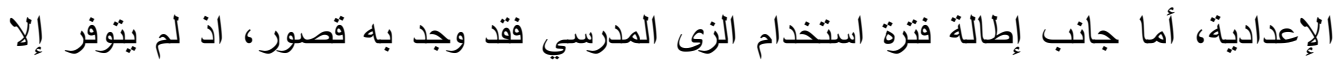

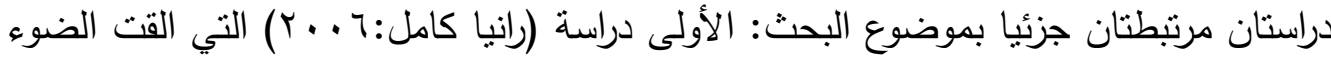

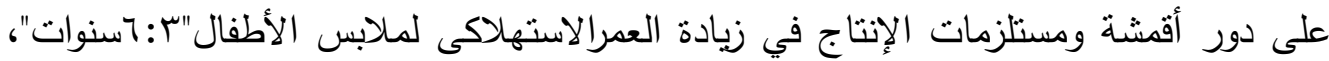

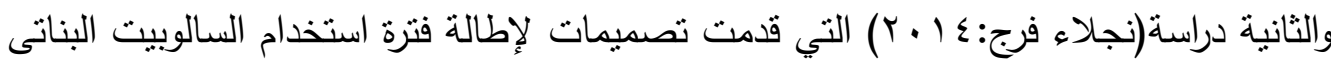

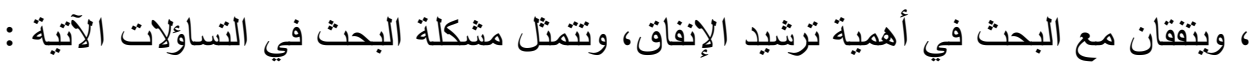

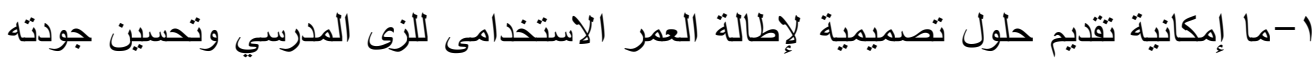
"وظيفيا-جماليا"؟

ץ-ما اراء المتخصصين فى التصاميم المقترحة ؟

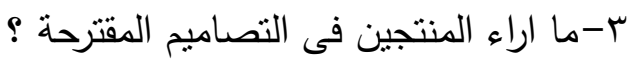

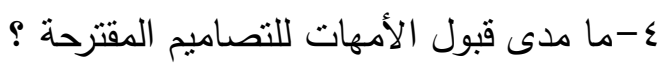

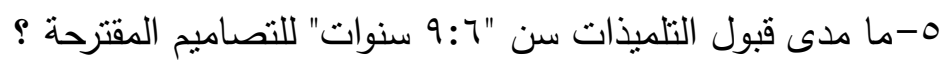

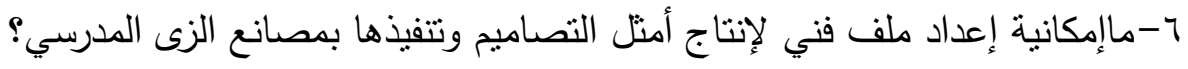

• Objectives : أهداف البحث

1- تقديم تصاميم مقترحة لإطالة العمر الاستخدامى للزى المدرسي وتحسين جودنه "وظيفيا-جماليا" .

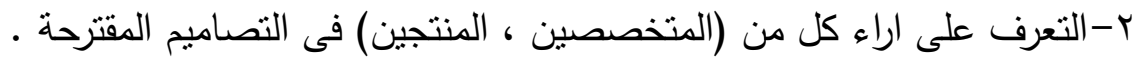

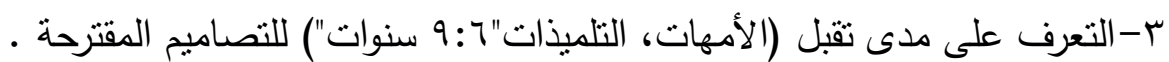

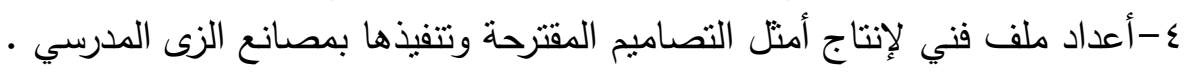

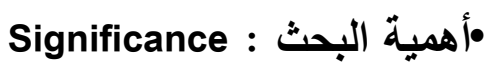
تخفيف العبء المادي على عاتق الأسرالمصرية بترشيد تكرار شراء الزى المدرسي .

• مروض البحث : Hypothesis 1-تحقق التصاميم المقترحة للزى المدرسي درجة قبول ونجاح في ضوء منوسطات تقييم

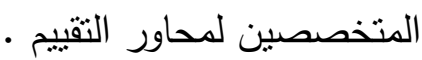
ץ-تحقق التصاميم المقترحة للزى المدرسي درجة قبول ونجاح في ضوء منوسطات نقييم

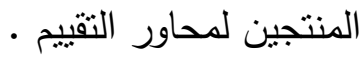


ب-تحقق التصاميم المقترحة للزى المدرسي درجة قبول ونجاح في ضوء منوسطات نقييم

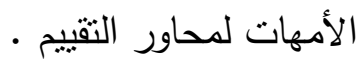
؟-تحقق التصاميم المقترحة للزى المدرسي درجة قبول ونجاح في ضوء منوسطات نقييم

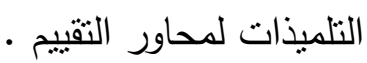

0- توجد فروق دالة إحصائيا بين التصاميم المقترحة للزى المدرسي في ضوء منوسطات التقبيم ككل .

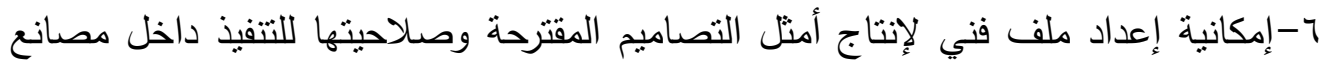

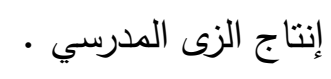

\section{Delimitations: حدود البحث}

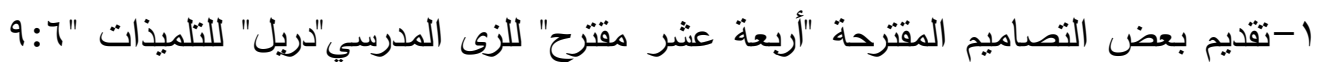
سنوات" بما يطل عمره الاستخدامى ويحسن جودته "وظيفيا-جماليا" ويلبى فى الوقت نفسه منطلبات التلميذات التى منها أن يكون "دريل"، فكان أكثر القطع تفضيلا للتلميذات

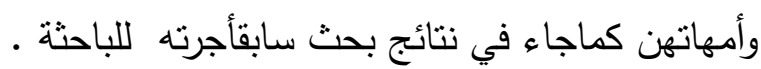

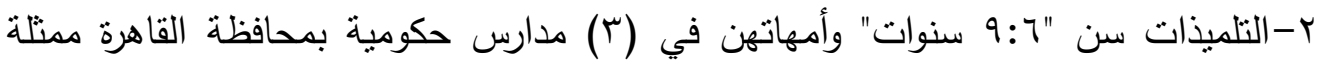

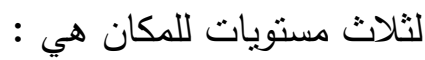

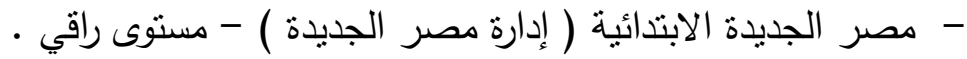

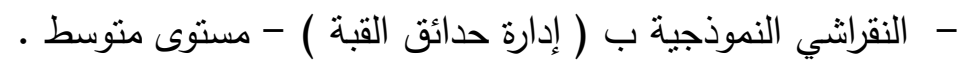

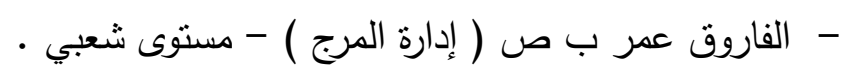

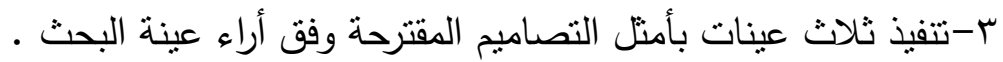

\section{• منهج البحث: Methodology}

اتبع البحث المنهج التجريبي لتقديم تصاميم مقترحة لإطالة العمر الاستخدامى للزى المدرسي

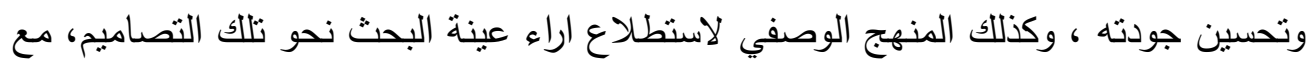

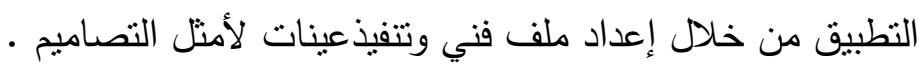

\section{Sample : عينة البحث}

تكونت عينة البحث من عدد " • 17 " مفردة قسمت كالتالي :

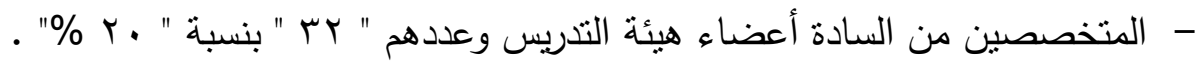

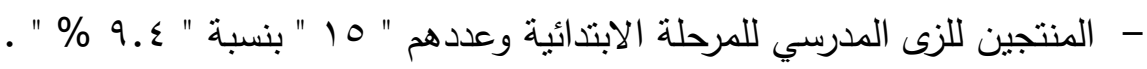

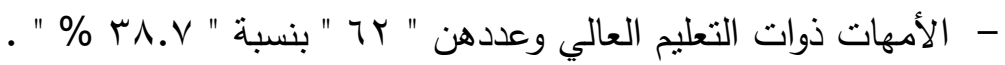

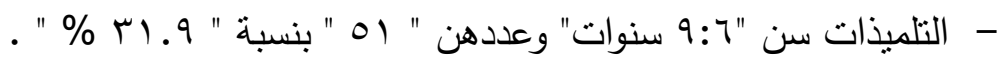
• أدوات البحث : أبدن 
1- مجموعة من الاستبيانات تضمنت :

- استبانه لمعرفة اراء المتخصصين فى التصاميم المقترحة .

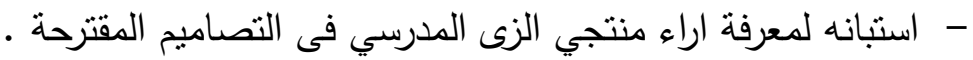

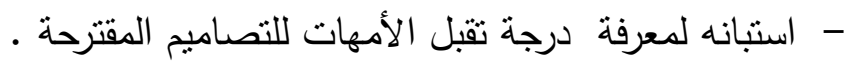

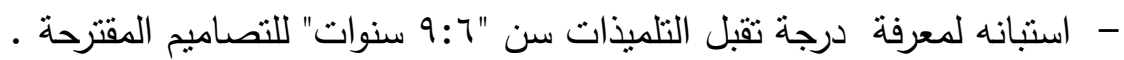

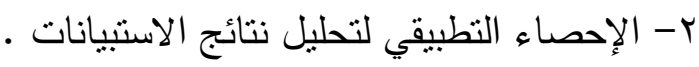

• مصطلحات البحث : مصن العمر الاستخدامى مصى :The consumer age: هو الفترة التى يتم فيها استعمال المنتج،

والعمرالاستخدامى للملبس هوفترة الاستفادة الفعلية منه (Patrick john:1995-35)

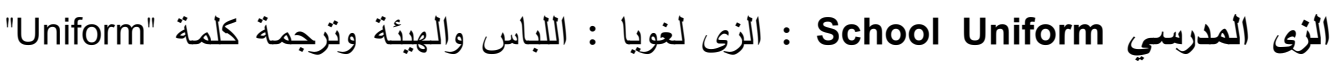

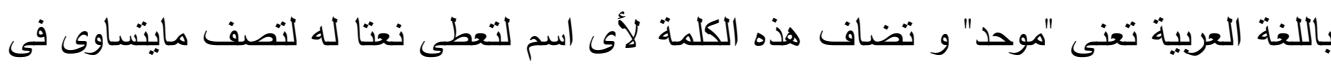

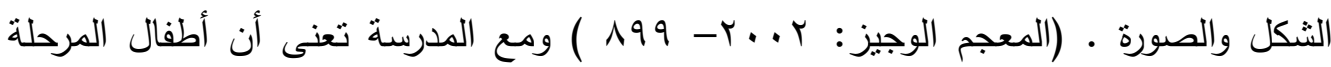

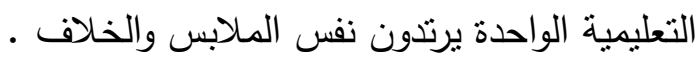

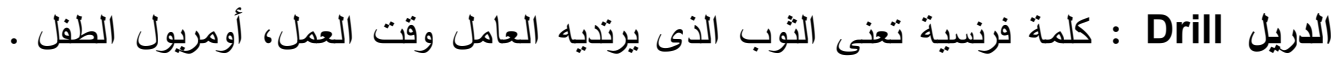

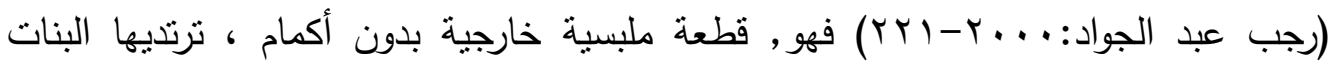

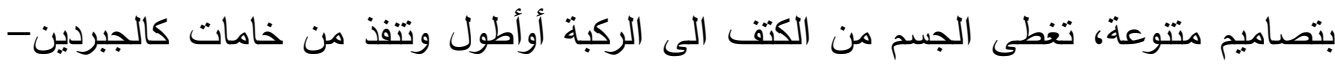
الكتان †الجينز (www.thefreedictionary.com/drill+cloth) الجودة Quality : (جاد) وجود : صار جيداً ، (أجاد) : أنى بالجيد ، ويقال: أجاد الثئ ،

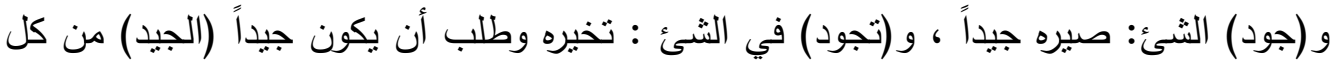

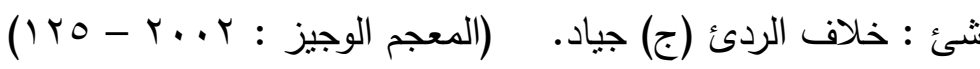

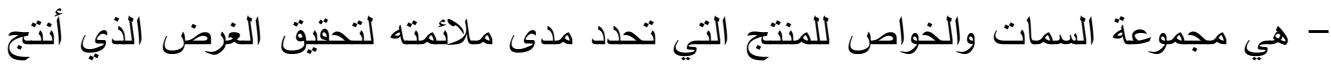

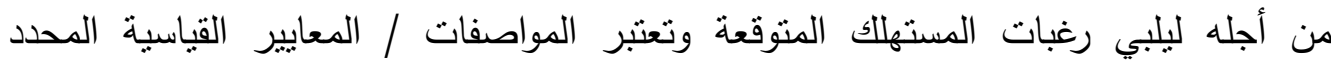

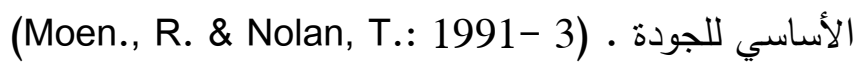
مرحلة الطقولة الوسطى Middle childhood : هى مرحلة تمند من سن السادسة الى التاسعة

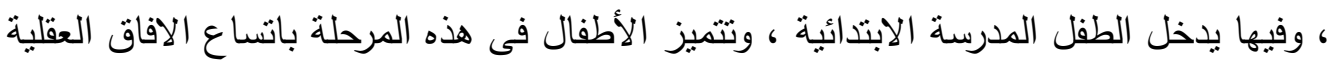

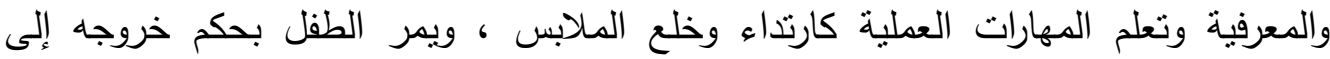

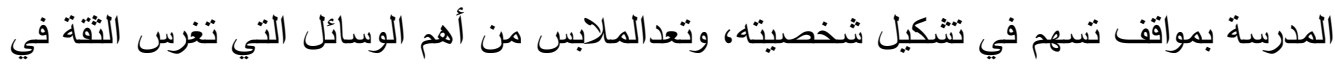

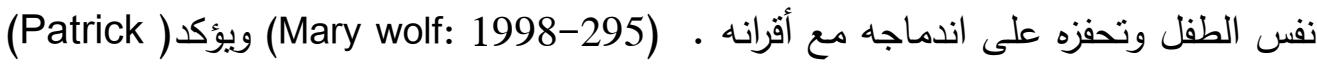
John:1995 على ضرورة وجود اليات تساعد فى تعديل الزى من حيث الطول والعرض ليلائم منطلبات النمو والحركة والنشاط المصاحبين . 
Procedures : إجراءات البحث

أولا : إعداد التصاميم المقترحة

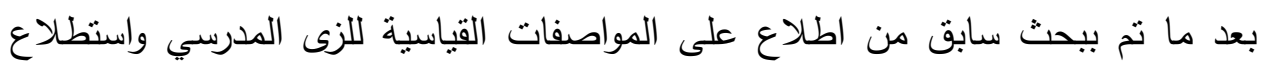

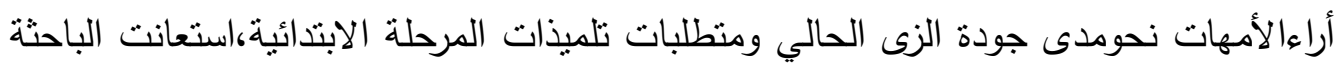

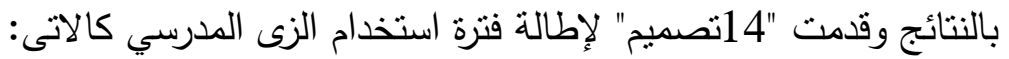
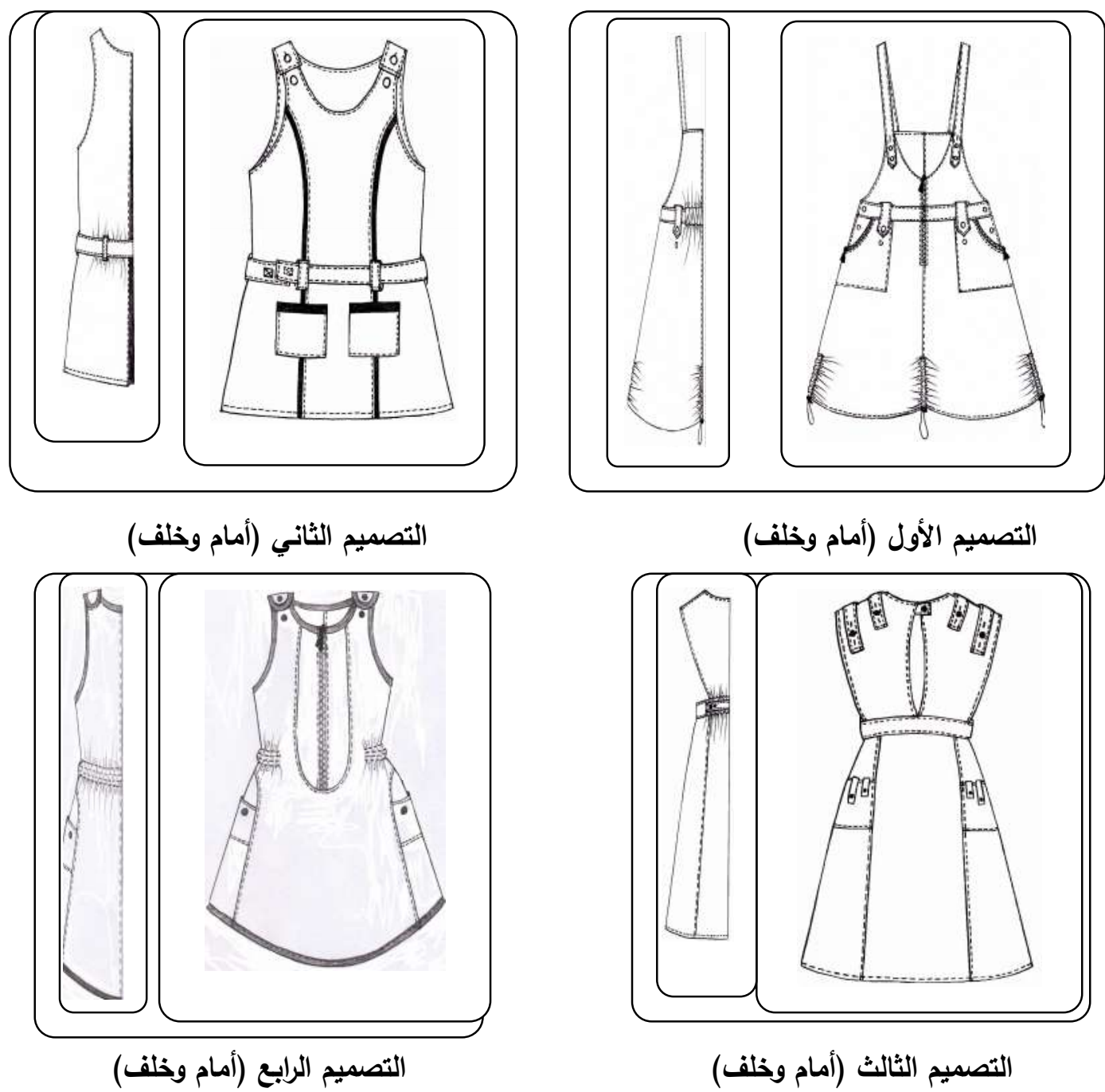


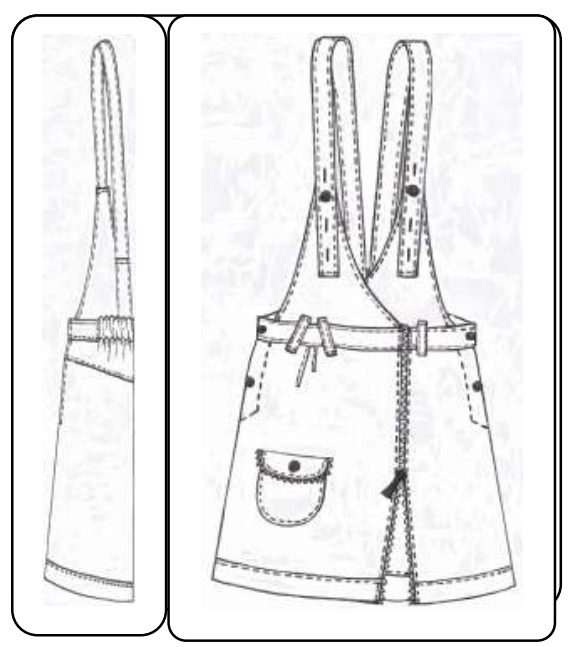

التصميم السادس (أمام وخلف)

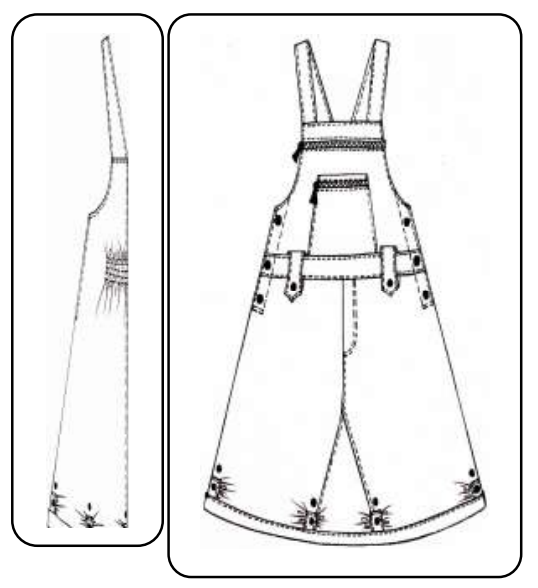

التصميم الثامن (أمام وخلف)
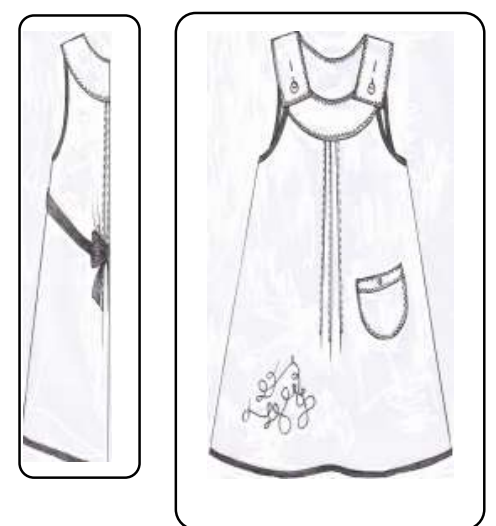

التصميم العاثُر (المام وخلف)
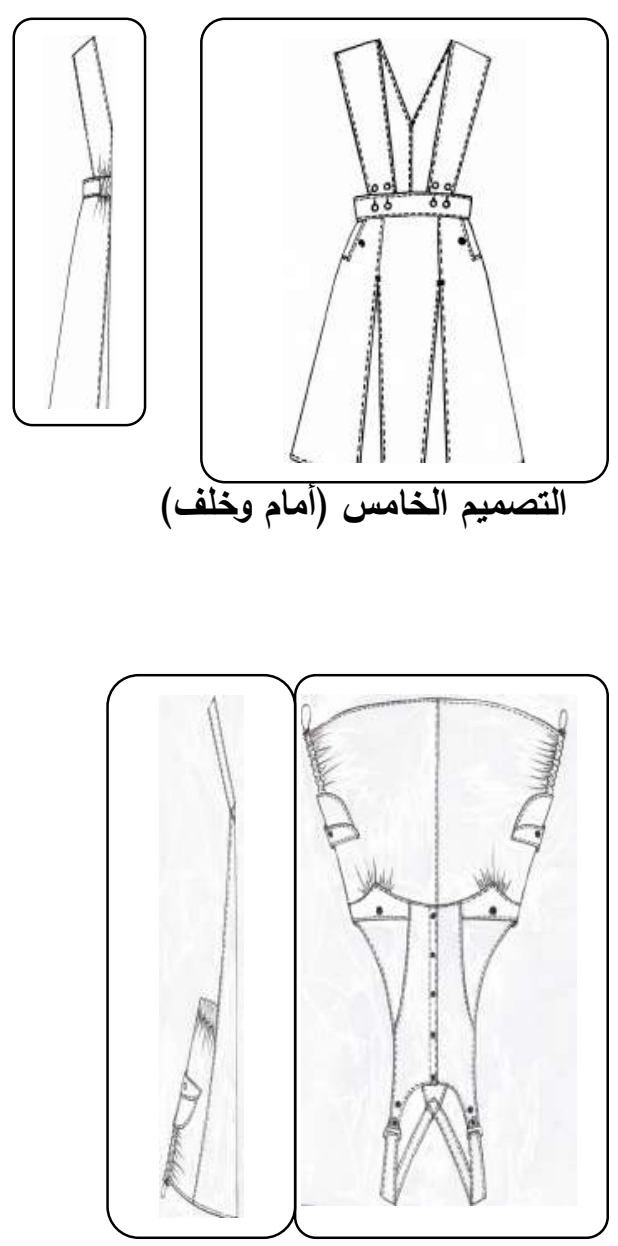

التصميم السابع (أمام وخلف)
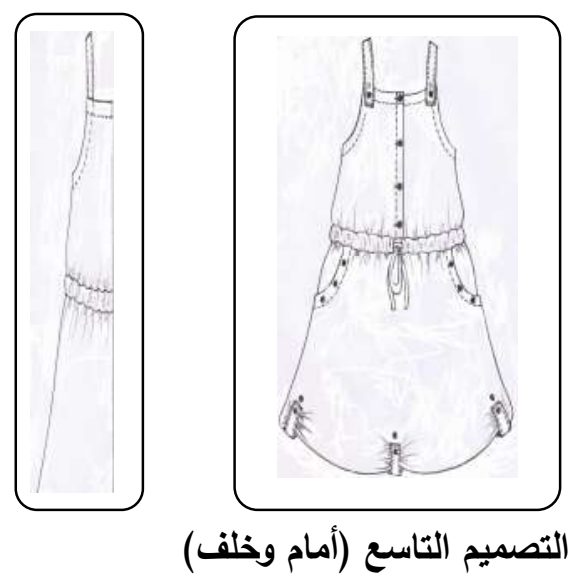


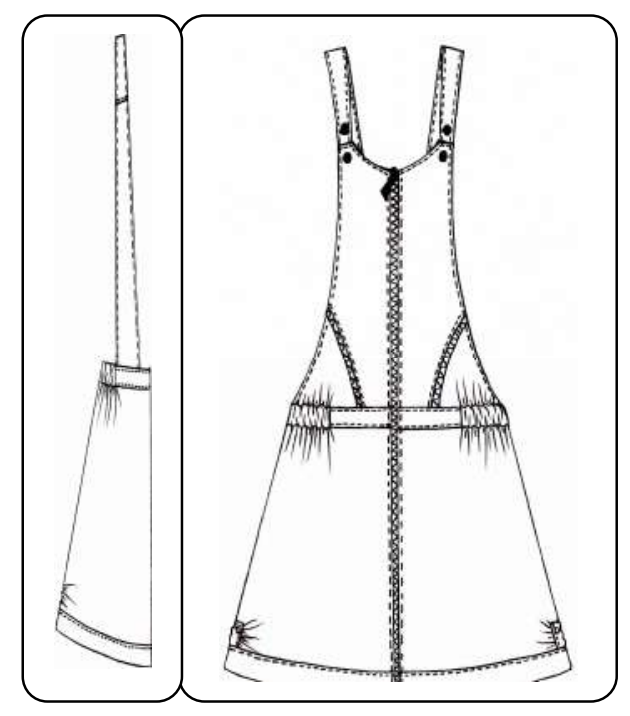

التصميم الثانى عشر (أمام وخلف)

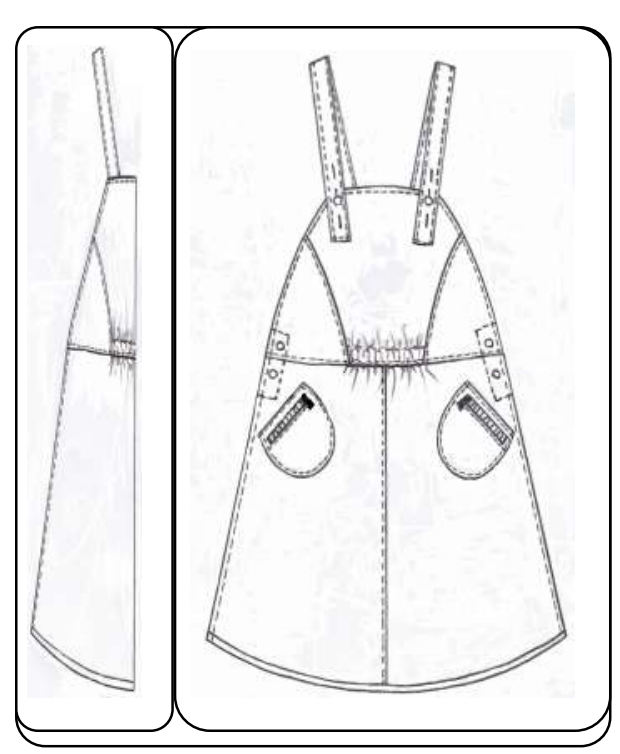

التصميم الرابع عشر (أمام وخلف)
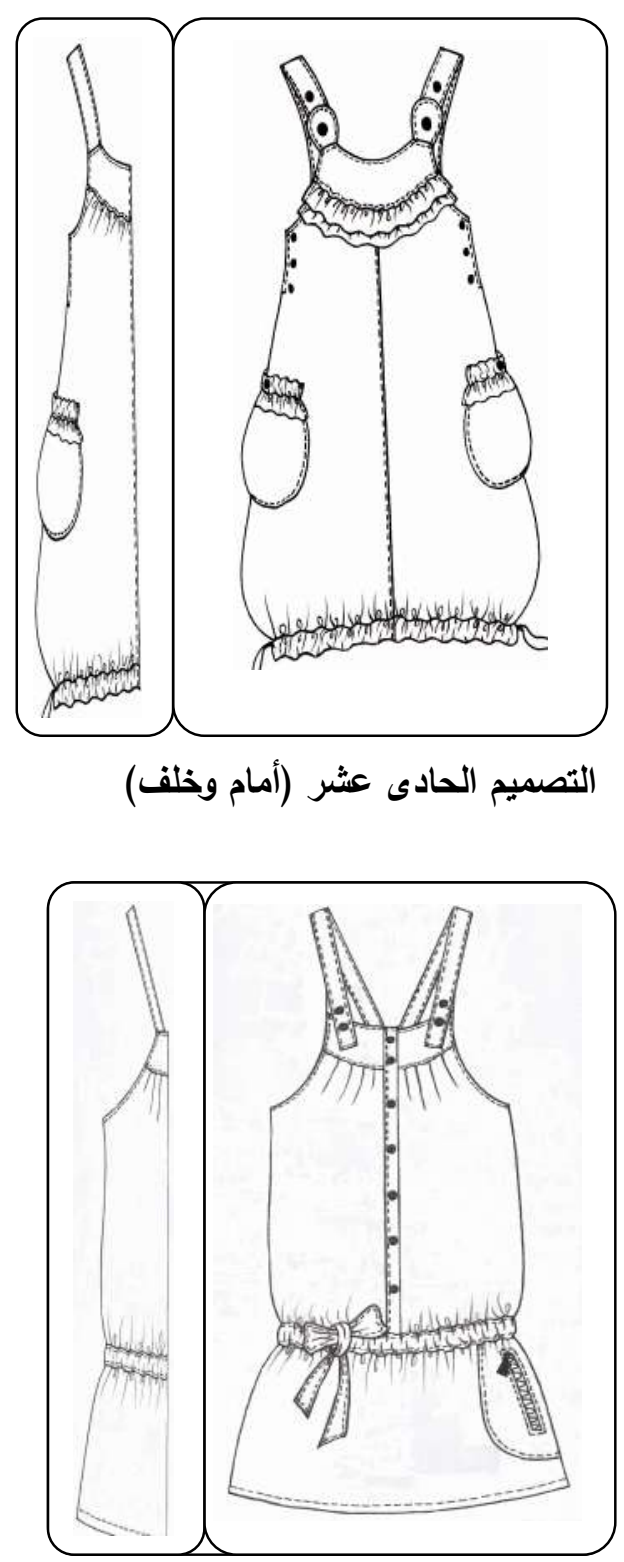

التصميم الثالث عثر (أمام وخلف)

بذلك نكون أجبنا على التساؤل الأول للبحث الحالي وينص عل(مامامكانية تقديم حلول تصميمية لإطالة العمر الاستخدامى للزى المدرسي وتحسين جودته "وظيفيا-جماليا") ؟ 


\section{ثُاتيا : تقييم التصاميم المقترحة}

بعد الانتهاء من إعداد التصاميم المقترحة "اربعة عشر مقترح" قامت الباحثة بإعداد

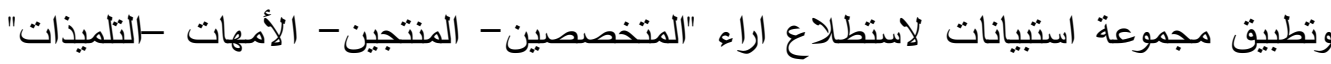

نحو تلك التصاميم كالاتى:

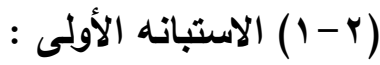

- الهذف من الاستبانة : تقييم التصاميم المقترحة للزى المدرسي من خلال الأساتذة

المتخصصين في مجال الملابس .

- وصف الاستبانة: اشتملت الاستبانة على "بr " عبارة مقسمة في أربعة محاور هي: - المحور الأول " تحقيق الأسس والقواعد الفنية " ويتضدن " ع " عبارات .

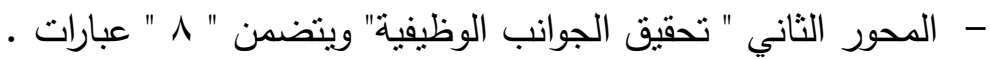

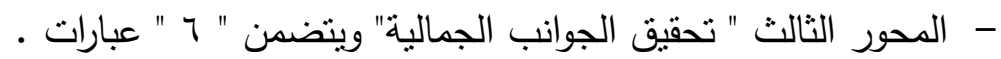
- المحور الرابع " تحقيق الجوانب الاقتصادية" ويتضمن " ه " عبارات ـ صدق الاستبانة "صدق المحكمين" : تم عرض الصورة المبدئية للاستبانة على مجموعة من

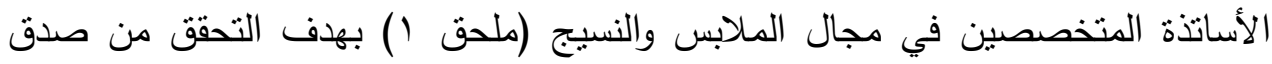
محتواها وإبداء الرأي فيها من حيث (مناسبة كل عبارة للمحور الخاص بها ، صحة صله الصياغة اللغوية للعبارات ، تسلسل وتتظيم العبارات) ، وقد تم حساب نسبة الاتفاق بين المحكمين والتي بلغت V. 19 9 ، وهى نسبة مرتفعة تدل على صدق الاستبانة وصلاحيتها

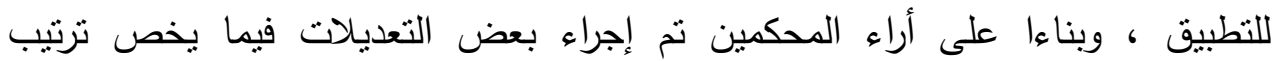

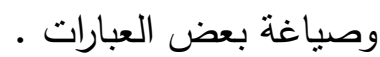
ثبات الاستبانة : نم حساب ثبات الاستبانة عن طريق معامل ثبات ألفا، ومعامل التجزئة

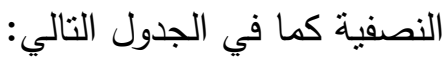
جدول ( ) معاملات ثبات ألفا والتجزئة النصفية لاستبانه أراء المتخصصين

\begin{tabular}{|c|c|c|}
\hline معامل التجزئة النصفية & معامل ألفا & \\
\hline$. .9 \cdot r-. .1 \cdot 1$ & .1099 & الاستبيان ككل \\
\hline
\end{tabular}

يتضح من الجدول السابق أن قيم معاملات ثبات ألفا والتجزئة النصفية مرتفعة وتنل على الأل ثبات الاسنبانة لقربها من الواحد. 


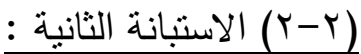

الهدف من الاستبانة تقييم التصاميم المقترحة للزى المدرسي من خلال السادة المنتجين - وصف الاستبانة : اشتملت الاستبانة على ثلاثة محاور هي (1- تحقيق الجوانب الوظيفية

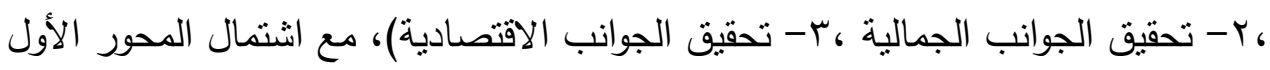
على "N" عبارات ، والمحور الثاني والثالث على "ه" عبارات. - صدق الاستبانة "صدق المحكمين": تم عرض الاستبانة على نفس محكمي الاستبانة الأولى ولى ألى بهدف التحقق من دقة الصياغة اللغوية للعبارات، وضوح وبساطة العبارات.وتم حساب نسبة الاتفاق بين المحكمين فبلغت87\%وهى نسبة تدل على صدق الاستبانة. - ثبات الاستبانة : نم حساب ثبات الاستبانة عن طريق معامل ثبات ألفا، ومعامل التجزئة النصفية كما في الجدول التالي: النيات

جدول (Y) معاملات ثبات ألفا والتجزئة النصفية لاستبانه أراء المنتجين

\begin{tabular}{|r|r|r|}
\hline الاستبيان كعل & \\
\hline
\end{tabular}

يتضح من الجدول السابق أن قيم معامل ثبات ألفا وكذلك التجزئة النصفية جاءت مرتفعة

$$
\begin{aligned}
& \text { وتدل على ثبات الاستبانة . } \\
& \text { : }
\end{aligned}
$$

- الهدف من الاستبانة : تقييم التصاميم المقترحة للزى المدرسي من خلال الأمهات . - وصف الاستبانة : اشتملت الاستبانة على ثلاثة محاور هي (1- تحقيق الجوانب الوظيفية

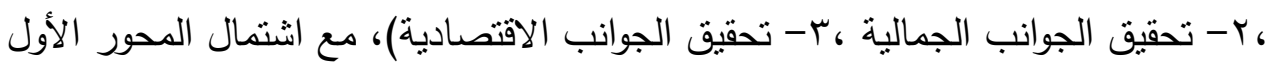

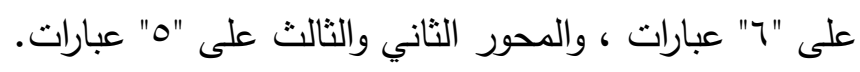
- صدق الاستبانة "صدق المحكمين": تم عرض الصورة المبئية للاستبانة على نفس محكمي

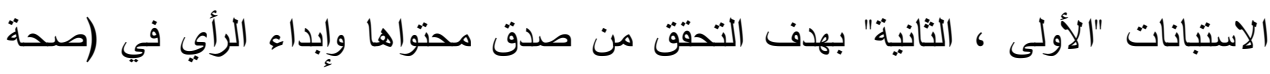
الصياغة اللغوية للعبارات ، وضوح وبساطة العبارات) وتم حساب نسبة الاتفاق بين المحكمين فبلغت 10\% وهى نسبة مرتفعة تدل على صدق الاستبانة . - ثبات الاستبانة : نم حساب ثبات الاستبانة عن طريق معامل ثبات ألفا، ومعامل التجزئة النصفية كما في الجدول التالي: 
جدول (r) معاملات ثبات ألفا والتجزئة النصفية لاستبانه أراء الأمهات

\begin{tabular}{|c|c|c|}
\hline معامل التجزئة النصفية & معامل ألفا & \\
\hline$. \wedge T 1-. \vee \vee \vee O$ & - . & الاستبيان ككل \\
\hline
\end{tabular}

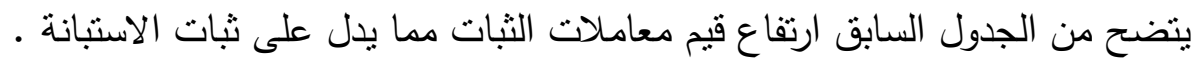

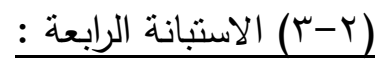

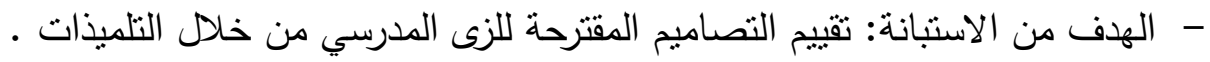

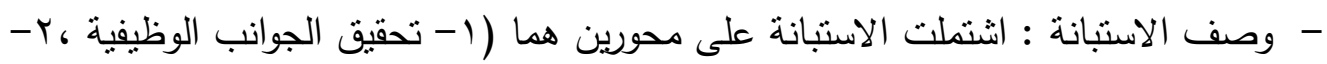

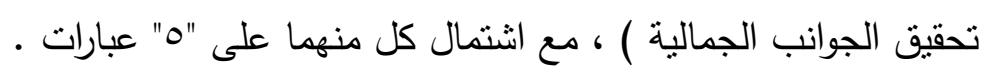
- صدق الاستبانة "صدق المحكمين" : تم عرض الاستبانة على محكمي الاستبيانات السابقة

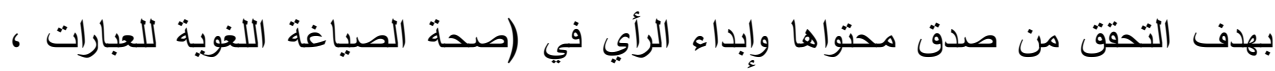

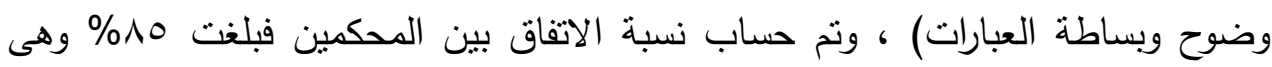

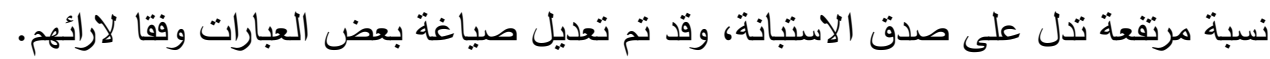

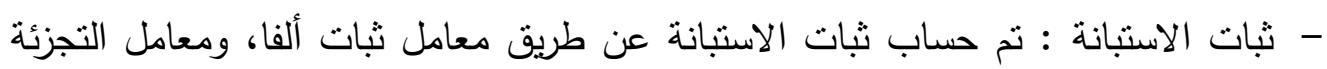
النصفية كما في الجدول التالي: جدول (ع ) قيم الثبات للاستبانة الرابعة

\begin{tabular}{|r|r|r|}
\hline | & \\
\hline
\end{tabular}

ويتضح من الجدول السابق ارتفاع قيم معاملات ثبات ألفا والتجزئة النصفية مما يدل على الهي ثبات الاستبانة .

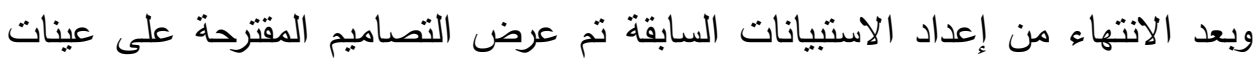

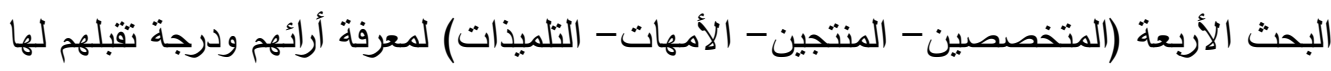

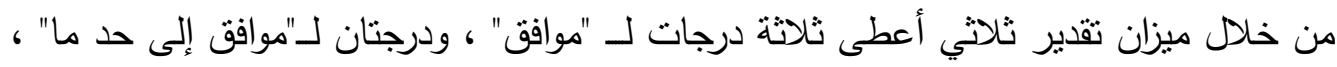

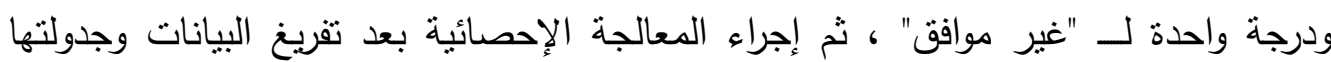

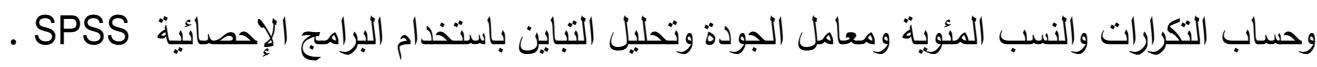
ثالثا : إعداد الملف الفني وإنتاج التصاميم المثلى ودئ بعد الانتهاء من إعداد التصاميم المقترحة وتقيمها تم اختيار ثناثة منها والتى حصلت

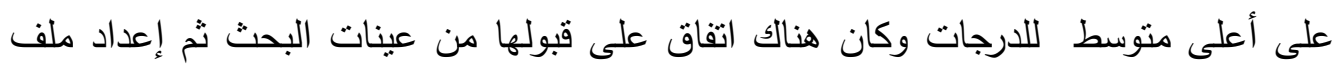
فني لإنتاج كل منهم على حده والذي يشتمل على

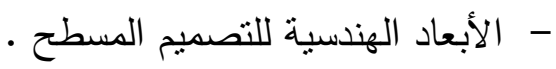


- مواصفات العينة ( المقاس المنفذ- مواصفات القماش والخامات المساعدة)

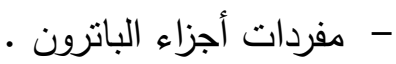

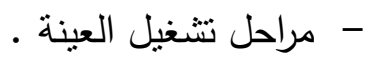

ثم إنتاج هذه التصاميم داخل مصنع (روز مارى للازياء المدرسية) وذلك بالخامات الموصى بها

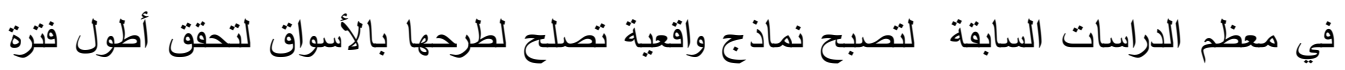
استخدام ، وأعلى مسنوى جودة بتكلفة مناسبة . لماست

\section{نتائج البحث ومناقشتها: Results and Discussion أولا: نتائج استبانه المتخصصين}

الجدول التالي يوضح منوسطات القيم النسبية لتقديرات المتخصصين للتصاميم محل الدراسة ، حيث تم في البداية وضع التقديرات المكافئة لكل عبارة ثم حساب القيم المتوسطة لكل محور وتحويلها إلى قيم نسبية ، ثم حساب القيم الدالة على معاملات الجودة من خلال

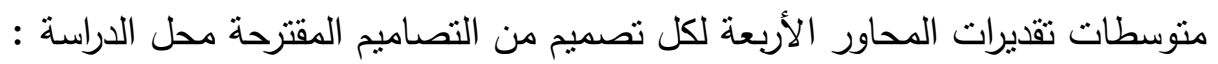
جدول (•) متوسط النسب المئوية لتقديرات المتخصصين لمحاور التقييم للتصاميم المقترحة

\begin{tabular}{|c|c|c|c|c|c|c|c|c|c|c|c|c|c|c|}
\hline 司 & 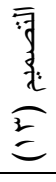 & 司 & 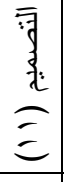 & $\begin{array}{l}\text { 司 } \\
\text { 全 } \\
\text { 三 }\end{array}$ & 司 & $\begin{array}{l}\text { 司 } \\
\frac{1}{3} \\
\text { క }\end{array}$ & $\begin{array}{l}\text { 司 } \\
\text { 昱 } \\
\text { 乏 }\end{array}$ & $\begin{array}{l}\text { 司 } \\
\text { 是 } \\
\end{array}$ & $\begin{array}{l}\text { 可 } \\
\text { 是 } \\
\text { o }\end{array}$ & $\begin{array}{r}\text { 司 } \\
\text { 利 } \\
0\end{array}$ & 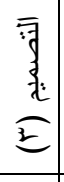 & 司 & $\exists$ & 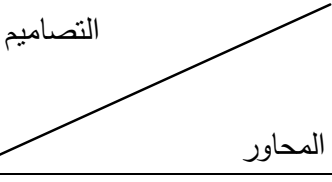 \\
\hline$\stackrel{\text { ź }}{\alpha}$ & $\bar{z}$ & $\begin{array}{l}r \\
\dot{\sigma} \\
\sigma\end{array}$ & 家 & $\dot{z}$ & $\stackrel{\circ}{\grave{k}}$ & $\frac{i}{2}$ & $\check{\sigma}$ & $\stackrel{\sigma}{\dot{\sigma}}$ & $\underset{2}{2}$ & r. & $\begin{array}{l}2 \\
\sigma \\
\sigma\end{array}$ & र & 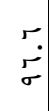 & والحورد الأول: تحقيق الأسس \\
\hline$\stackrel{2}{j}$ & $\bar{z}$ & $\stackrel{0}{i}$ & $\frac{2}{\dot{\alpha}}$ & $\stackrel{\vdots}{\vdots}$ & 产 & $\stackrel{\circ}{\sigma}$ & $\dot{\xi}$ & $\stackrel{r}{\check{\sigma}}$ & $\underset{v}{j}$ & 芦| & $\begin{array}{l}\sigma \\
\dot{j}\end{array}$ & $\begin{array}{l}\prec \\
\vdots \\
\vdots\end{array}$ & 官 & الدوانب الوظيفية الثاني: تحقيق \\
\hline$\stackrel{3}{j}$ & $\frac{2}{\dot{z}}$ & $\begin{array}{l}0 \\
\dot{\sigma} \\
\sigma\end{array}$ & $\begin{array}{l}w \\
2 \\
2\end{array}$ & $\bar{z}$ & 家 & $\bar{z}$ & 玄 & $\stackrel{2}{j}$ & 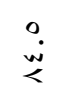 & 管 & $\frac{2}{\sigma}$ & $=$ & $\begin{array}{l}\sigma \\
\sigma \\
\sigma\end{array}$ & الجوانب الجمالية: تحقيق \\
\hline ji & $\stackrel{2}{\dot{z}}$ & $\frac{2}{2}$ & $\grave{\dot{z}}$ & $\stackrel{0}{i}$ & $\stackrel{0}{i}$ & $\stackrel{2}{\dot{\sigma}}$ & 宾 & $\grave{\dot{\sigma}}$ & 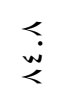 & $\stackrel{\sigma}{\dot{2}}$ & $\underset{\sigma}{\dot{\alpha}}$ & र & $\begin{array}{l}w \\
\dot{\sigma}\end{array}$ & الجوانب الاقتصادية الحقية : تحقيق \\
\hline$\stackrel{w}{\dot{s}}$ & $\frac{2}{\dot{z}}$ & $\begin{array}{l}2 \\
\dot{w} \\
\sigma\end{array}$ & $2^{2}$ & $\check{j}$ & $\underset{\substack{0 \\
\dot{z}}}{ }$ & $\frac{\sigma}{\sigma}$ & $\begin{array}{l}2 \\
\dot{z}\end{array}$ & $\stackrel{\sigma}{\sigma}$ & 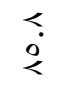 & 紊 & ${ }^{\sigma}$ & z & $\begin{array}{l}r \\
\sigma \\
\sigma\end{array}$ & معامل الجودة\%\% \\
\hline
\end{tabular}

يتضح من الجدول السابق أن جميع التصاميم سجلت نسب مرتفعة من وجهة نظر المتخصصين تراوحت بين "ج. . 1-9\%\%" كان أفضلها التصاميم الثلاث : الثالث ثم الرابع

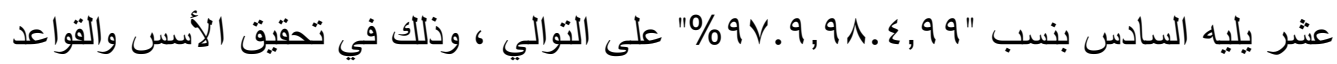


الفنية وكذلك الجوانب الوظيفية والجمالية والذى ينعكس على صحة التلميذات الجسمية والنفسية ومن ثم الاستجابة والدافعية للتعليم، بالاضافة الى اطالة فترة استخدام الزى ومما يعكسه على لى ليه اقتصاديات الأسر المصرية.وبذلك يتحقق الفرض الأول الذي ينص على ألى أن التصاميم المقترحة للزى المدرسي تحقق درجة قبول ونجاح في ضوء منوسطات تقييم المتخصصين لمحاور التقييم. والثكل( () يوضح الفروق في معاملات الجودة للتصاميم حيث تقديرات المتخصصين:

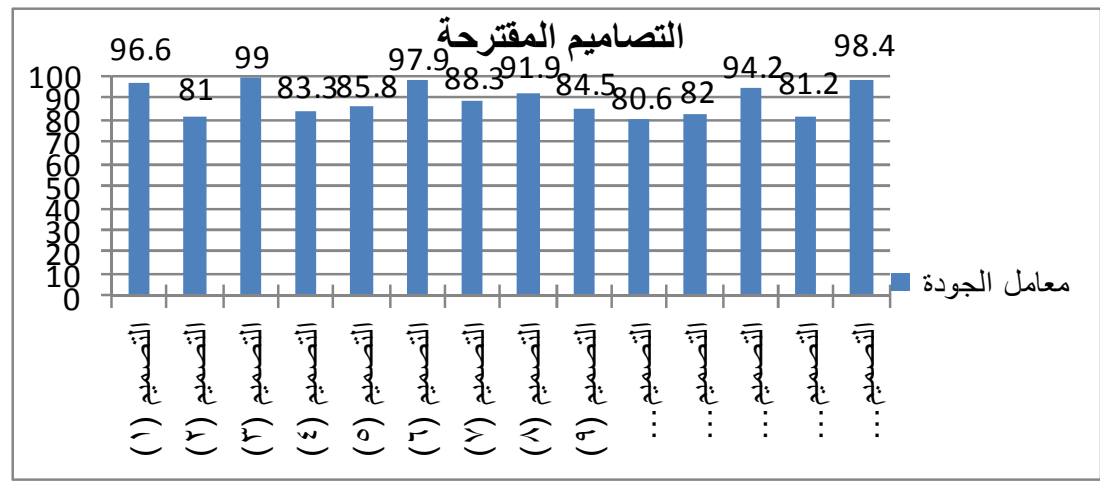

شكل ( () معاملات الجودة للتصاميم المقترحة محل الدراسة من حيث تقديرات المتخصصين ويتضح من الثكل السابق تقارب معاملات الجودة للتصاميم المقترحة فتتراوح

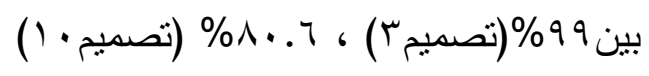

ولإيجاد الفروق بين متوسطات تقديرات المتخصصين تم حساب تحليل التباين ثنائي

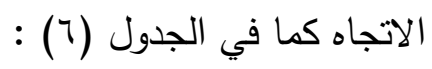

\begin{tabular}{|c|c|c|c|c|c|c|}
\hline F crit & P-value & $F$ & MS & DS & SS & مصدر التباين \\
\hline 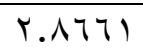 & ..r人 & $r .1 . \leqslant \varepsilon$ & $\{r .00\}$ & $\varepsilon$ & IVE.YY & المحاور \\
\hline r.VI.9 & $. .701 \leqslant$ &. .779 & 9.r人тr & 0 & $\leqslant 7.9 \pi 1$ & التصاميج \\
\hline
\end{tabular}

جدول(؟) نتائج تحليل التباين ثنائي الاتجاه بين محاور الاستبانة الأولى والتصاميم المقترحة

يتضح من الجدول السابق وجود اختلاف معنوي بين متوسطات تقديرات المتخصصين لمحاور التقييم عند مستوى معنويةه...، بينما لايوجد اختلاف بين منوسطات تقديرات

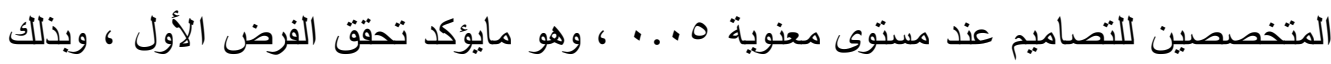

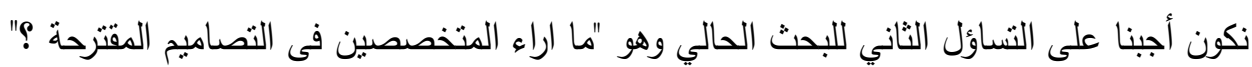
ثانيا: نتائج استبانه منتجي الزى المدرسي

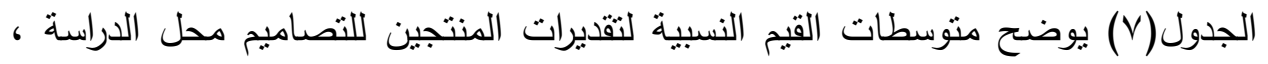

وقد تم الحساب بنفس الطريقة السابقة : 
جدول (V) متوسط النسب المئوية لتقديرات المنتجين لمحاور التقييم للتصاميم المقترحة

\begin{tabular}{|c|c|c|c|c|c|c|c|c|c|c|c|c|c|c|}
\hline 可 & 司 & 司 & 司 & $\frac{\text { 可 }}{\stackrel{3}{\vdots}}$ & $\frac{\bar{⿹}}{\frac{3}{3}}$ & 司 & 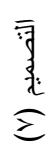 & 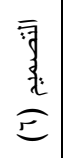 & 可 & $\frac{5}{5}$ & 司 & 司 & 司 & المحاور \\
\hline$\dot{\sigma}$ & 之 & $\ddot{\sigma}$ & 点 & $\dot{z}$ & 之 & $\frac{1}{\sigma}$ & $\bar{\sigma}$ & $\ddot{\sigma}$ & $\dot{\sigma}$ & ? & $\dot{\sigma}$ & $\dot{z}$ & $\dot{\sigma}$ & الجحور الأول: تحقيق \\
\hline$\underset{\sigma}{\grave{\sigma}}$ & $\stackrel{2}{2}$ & $\tilde{\sigma}$ & 总 & $\dot{z}$ & $\dot{j}$ & $\frac{2}{\sigma}$ & $\stackrel{\check{\sigma}}{\sigma}$ & $\bar{\sigma}$ & $\begin{array}{l}< \\
\dot{\sigma} \\
\dot{\alpha}\end{array}$ & ז & $\bar{j}$ & $\stackrel{2}{\dot{z}}$ & $\begin{array}{l}2 \\
0 \\
\sigma\end{array}$ & الجوانب الجمالية الثاني: تحقيق \\
\hline 方 & 京 & $\underset{\sigma}{\sigma}$ & "u & $\stackrel{\sim}{\check{z}}$ & $\grave{\gtrless}$ & $\underset{\sigma}{\sigma}$ & $\underset{\Sigma}{2}$ & $\stackrel{2}{*}$ & $\underset{\dot{x}}{\stackrel{<}{\alpha}}$ & 宾 & $\bar{\sigma}$ & $\stackrel{2}{\dot{z}}$ & $\begin{array}{c}\bar{c} \\
\sigma \\
\sigma\end{array}$ & الدوانب الإقتصادية: تحقيق \\
\hline$\dot{\sigma}$ & < & $\dot{\sigma}$ & $\frac{2}{2}$ & $\dot{z}$ & ই & $\frac{1}{\sigma}$ & $\bar{\sigma}$ & $\dot{\sigma}$ & $\stackrel{\dot{q}}{<}$ & $\stackrel{0}{2}$ & $\dot{\sigma}$ & z & $\begin{array}{l}\dot{\sigma} \\
\sigma\end{array}$ & معامل \\
\hline
\end{tabular}

يتضح من الجدول السابق أن جميع التصاميم المقترحة سجلت نسب مرتفعة تراوحت بين

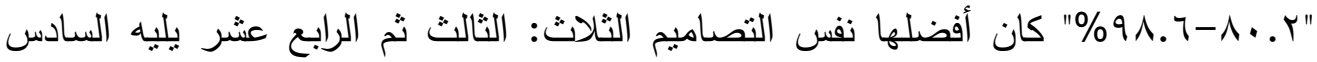

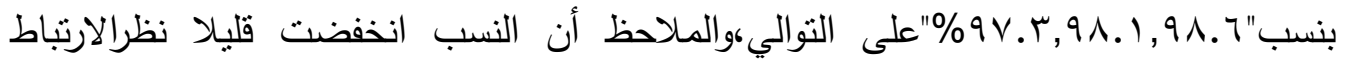

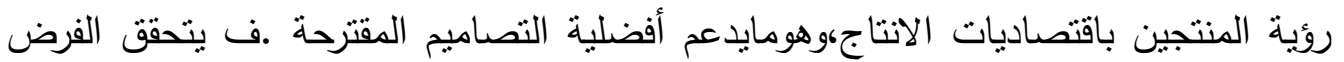
الثاني وينص على أن التصاميم المقترحة للزى المدرسي تحقق قبول ونجاح في ضوهاء متوسطات تقييم المنتجين لمحاور التقييم •

والثكل(ץ) يوضح الفروق في معاملات الجودة للتصاميم من حيث تقديرات المنتجين:

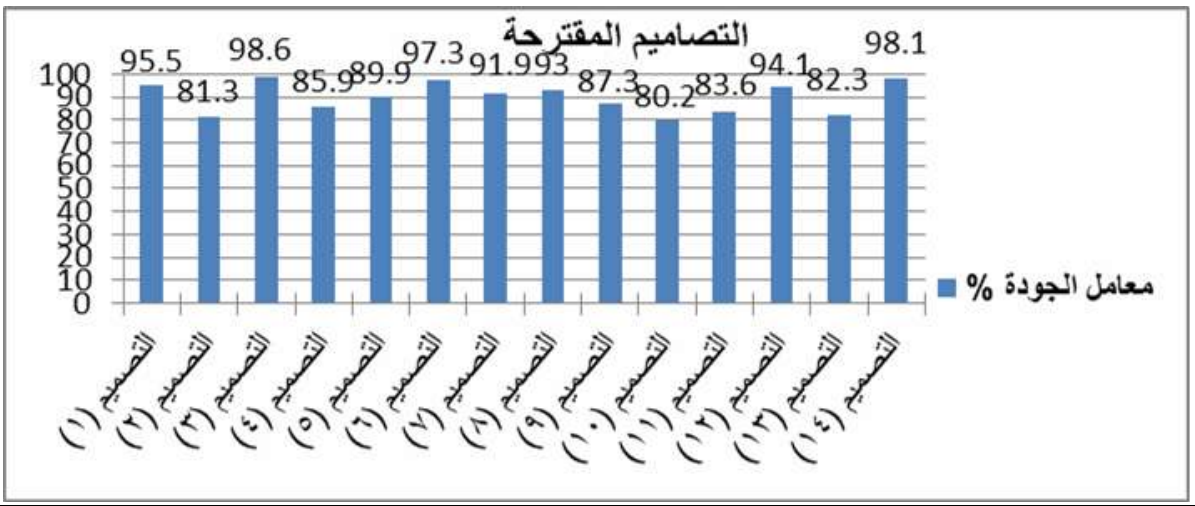

شكل (Y) معاملات الجودة للتصاميم المقترحة محل الدراسة من حيث تقديرات المنتجين

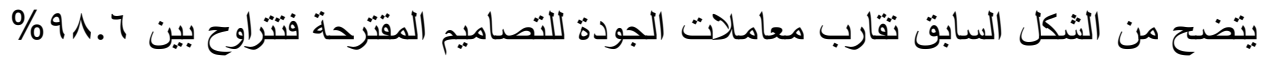

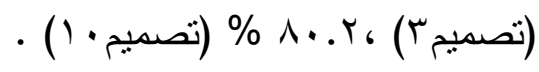


ولإيجاد الفروق بين متوسطات تقديرات المنتجين تم حساب تحليل التباين ثنائي الاتجاه

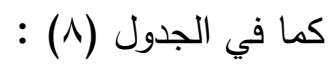

جدول(^) نتائج تحليل التباين ثنائي الاتجاه بين محاور الاستبانة الثانية والتصاميم المقترحة

\begin{tabular}{|c|c|c|c|c|c|c|}
\hline F crit & $\mathrm{P}$-value & $\mathrm{F}$ & MS & DS & SS & مصدر التباين \\
\hline r.АT7। & $\ldots 11$ & אזT. & OV.VTV & $\varepsilon$ & rTI..V & الدحاور \\
\hline r.V1.9 & $\ldots 9 \vee \vee 9$ & Y.IVO & rᄉ.990 & 0 & $1 \leqslant \leqslant .9 V$ & التصامبح \\
\hline
\end{tabular}

يتضح من الجدول وجود اختلاف معنوي بين متوسطات تقديرات المنتجين لمحاور التقييم عند مستوى معنويةه...، بينمالا يوجد اختلاف معنوي بين متوسطات تقديرات المنتجين

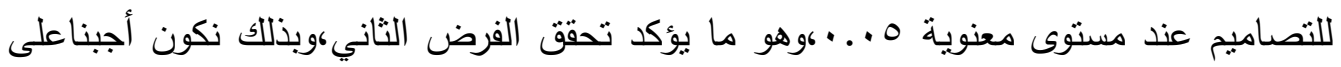

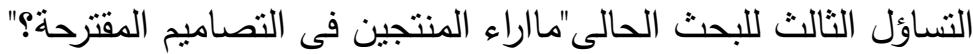

\section{ثالثا: نتائج استبانه الأمهات}

الجدول (9) يوضح متوسطات القيم النسبية لتقديرات الأمهات للتصاميم محل الدراسة ،

وقد تم الحساب بنفس الطريقة السابقة :

جدول (9) منوسط النسب المئوية لتقديرات الأمهات لمحاور الثقييم للتصاميم المقترحة

\begin{tabular}{|c|c|c|c|c|c|c|c|c|c|c|c|c|c|c|}
\hline 泰 & 司 & $\begin{array}{l}\frac{1}{3} \\
\frac{3}{2} \\
=\end{array}$ & 司 & $\frac{\text { 可 }}{\frac{3}{2}}$ & 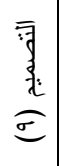 & 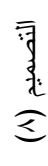 & 司 & 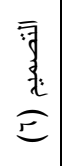 & 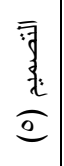 & $\frac{\sqrt{3}}{\stackrel{3}{*}}$ & 可㟟 & $\frac{\overline{1}}{2}$ & $\stackrel{\text { 司 }}{\text { 景 }}$ & المحاور \\
\hline$\sigma^{\sigma}$ & $\stackrel{0}{2}$ & $\dot{\sigma}$ & $\gtreqless$ & $2^{2}$ & $\dot{\sigma}$ & $\dot{\sigma}$ & $\dot{\sigma}$ & $\dot{\sigma}$ & $\dot{\sigma}$ & $\sigma_{\alpha}^{\sigma}$ & $\dot{\sigma}$ & 安 & $\dot{\sigma}$ & الحور الأول : تحقيق \\
\hline$\sigma^{\sigma}$ & zí & $\dot{\sigma}$ & $\gtreqless$ & $2^{2}$ & $\dot{\sigma}$ & $\dot{\sigma}$ & $\dot{\sigma}$ & $\dot{\sigma}$ & $\dot{\sigma}$ & $\stackrel{\dot{\sigma}}{<}$ & $\dot{\sigma}$ & 光 & $\vec{\sigma}$ & الجوانب الجمالية : تحقيق \\
\hline$\sigma_{\sigma}^{\sigma}$ & г & $\dot{\sigma}$ & 安 & $\dot{z}$ & $\dot{\sigma}$ & $\stackrel{\omega}{\sigma}$ & $\sigma^{2}$ & $\dot{\sigma}$ & $\dot{\sigma}$ & $\dot{\Sigma}$ & $\sigma_{\sigma}^{\sigma}$ & $\dot{<}$ & $\ddot{\sigma}$ & الدوانب الآتصادية : تحقيق \\
\hline$\sigma$ & $\stackrel{0}{2}$ & $\stackrel{\circ}{\sigma}$ & ই & ₹ & $\dot{\sigma}$ & $\tilde{\sigma}$ & $\sigma$ & $\sigma$ & $\dot{\sigma}$ & ২ & $\sigma^{\sigma}$ & 2 & $\vec{\sigma}$ & معامل الجودة \% \\
\hline
\end{tabular}

يؤكد الجدول السابق ما رآه كل من المتخصصين والمنتجين ويشترك معهم في أفضلية

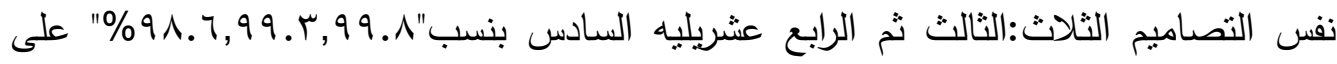

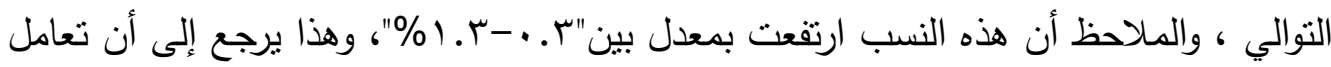
الأمهات مع الزى المدرسي يكون طويل المدى وأكثر احتكاك وتفاعل ، بينماعتمدت أراء

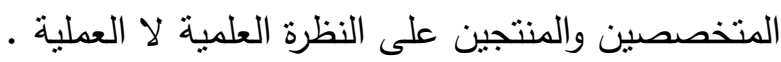


وبذللك يتحقق الفرض الثالث والذي ينص على أن التصاميم المقترحة للزى المدرسي "دريل" تحقق درجة قبول ونجاح في ضوء منوسطات تقييم الأمهات لمحاور التقييم. والثكل (ب) يوضح الفروق في معاملات الجودة للتصاميم من حيث تقديرات الأمهات:

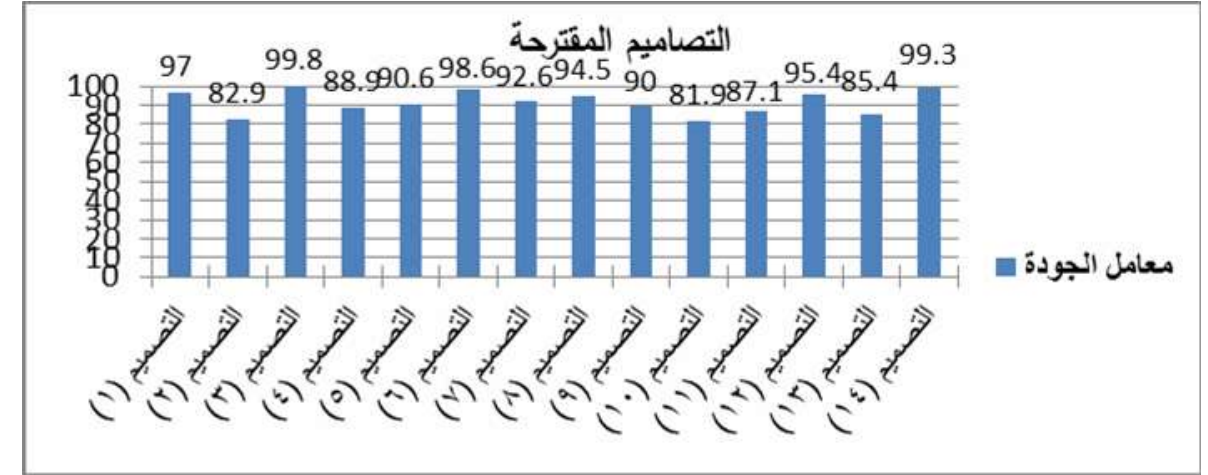

شكل (T) معاملات الجودة للتصاميم المقترحة محل الدراسة من حيث تقديرات الأمهات

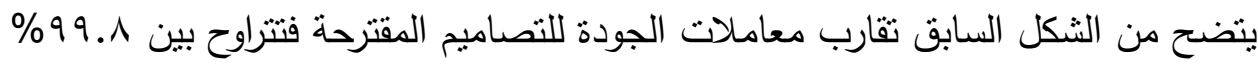

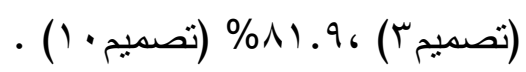

ولإيجاد الفروق بين متوسطات تقديرات الأمهات تم حساب تحليل التباين ثنائي الاتجاه كما

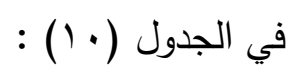

\begin{tabular}{|c|c|c|c|c|c|c|}
\hline F crit & $\mathrm{P}$-value & $\mathrm{F}$ & MS & DS & SS & مصدر التباين \\
\hline r.ATt & .01119 & $r .101 T$ & $r \Lambda .019$ & $\varepsilon$ & $10 \varepsilon . . V$ & المحاور \\
\hline$r . V 1 . q$ & $\ldots \mid v$ & $0 . \wedge T \leq \Lambda$ & $1.0 . .1$ & 0 & oro..r & التصاميج \\
\hline
\end{tabular}

جدول( • () نتائج تحليل التباين ثنائي الاتجاه بين محاور الاستبانة الثالثة والتصاميم المقترحة

يتضح من الجدول وجود اختلاف معنوي بين منوسطات تقديرات الأمهات لـحاورالتقييم عند مستوى معنويةه... بينمالايوجد اختلاف معنوي بين متوسطات تقديرات الأمهات

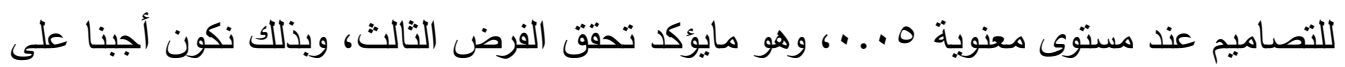

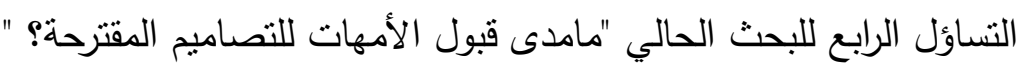
لإبعا: نتائج استبانه التلميذات

الجدول (1) (1) يوضح متوسطات القيم النسبية لتقديرات التلميذات سن "ج:9 سنوات" للتصاميم المقترحة، وقد تم الحساب بنفس الطريقة المستخدمة مع الاستبيانات السابقة: 
جدول (11) متوسط النسب المئوية لتقديرات التلميذات لمحاور التقييم للتصاميم المقترحة

\begin{tabular}{|c|c|c|c|c|c|c|c|c|c|c|c|c|c|c|}
\hline $\begin{array}{l}\frac{9}{3} \\
\frac{3}{3} \\
=\end{array}$ & 可 & $\frac{\overline{0}}{\frac{3}{2}}$ & 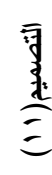 & $\frac{\text { 可 }}{\frac{x^{2}}{2}}$ & $\frac{\text { 哥 }}{\text { 是 }}$ & $\frac{\text { 可 }}{\text { 是 }}$ & 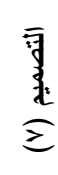 & $\begin{array}{l}\text { 可 } \\
\text { 虽 } \\
\text { 己 }\end{array}$ & 司 & $\frac{\bar{y}}{\stackrel{3}{*}}$ & $\frac{\text { 可 }}{\text { 录 }}$ & $\frac{\text { 司 }}{\text { 是 }}$ & 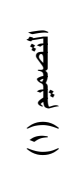 & التصاميم \\
\hline $\begin{array}{l}9 V \\
.0\end{array}$ & $\begin{array}{ll}\text { n } \\
.1\end{array}$ & $\begin{array}{l}4 \\
9 \\
\end{array}$ & . & $\Lambda$ & $\begin{array}{l}10 \\
.9\end{array}$ & $\begin{array}{l}q 1 \\
\text { ar }\end{array}$ & $\begin{array}{l}19 \\
. \wedge\end{array}$ & $\begin{array}{l}97 \\
.9\end{array}$ & $\begin{array}{l}\text { AV } \\
.7\end{array}$ & 10 & $\begin{array}{l}99 . \\
0\end{array}$ & $\begin{array}{l}\lambda r . \\
\varepsilon\end{array}$ & $\begin{array}{c}9 \leq . \\
9\end{array}$ & الجوانب الوظيفية الأول : تحقيق \\
\hline $\begin{array}{l}9 \vee \\
. \varepsilon\end{array}$ & $\begin{array}{l}\text { Ar } \\
.0\end{array}$ & $\begin{array}{l}94 \\
. \wedge\end{array}$ & N & $\begin{array}{l}19 \\
.9\end{array}$ & $\begin{array}{l}\wedge \varepsilon \\
. \wedge\end{array}$ & 91 & $\begin{array}{l}19 \\
.0\end{array}$ & $\begin{array}{l}97 \\
.7\end{array}$ & $\begin{array}{l}\text { AV } \\
. \top\end{array}$ & $\begin{array}{l}\Lambda \varepsilon \\
. r\end{array}$ & $\begin{array}{l}99 . \\
0\end{array}$ & ^. & $\begin{array}{c}94 . \\
1\end{array}$ & الجوانب الجمالية : تحقيق \\
\hline $\begin{array}{l}9 \vee \\
.0\end{array}$ & $\begin{array}{ll}\lambda r \\
. \wedge\end{array}$ & $\begin{array}{l}0 \\
\\
\end{array}$ & $\begin{array}{ll}\lambda r \\
\varepsilon\end{array}$ & $\begin{array}{l}\wedge . \\
.0\end{array}$ & $\begin{array}{l}\text { no } \\
\text { r. }\end{array}$ & $\begin{array}{l}91 \\
. v\end{array}$ & $\begin{array}{l}\wedge 9 \\
. V\end{array}$ & $\begin{array}{l}97 \\
.1\end{array}$ & $\begin{array}{l}\text { AV } \\
.1\end{array}$ & $\begin{array}{l}\wedge \varepsilon \\
.1\end{array}$ & $\begin{array}{l}99 . \\
0\end{array}$ & $\begin{array}{l}11 . \\
9\end{array}$ & $9 \varepsilon$. & معامل الجودة\% \\
\hline
\end{tabular}

يؤكد الجدول السابق ما رأته عينات البحث الثنلاث السابقة، ويشترك معهم في أفضلية

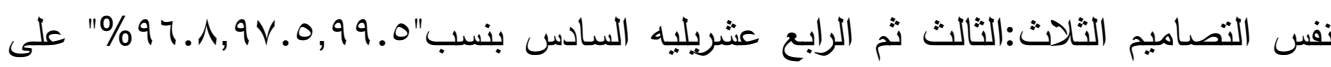

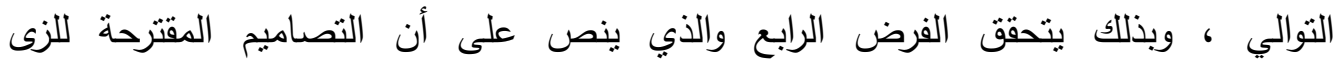
المدرسي"دريل" تحقق درجة قبول ونجاح في ضوء منوسطات تقييم التلميذات سن "ج:وسنوات

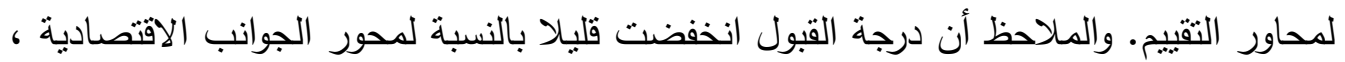

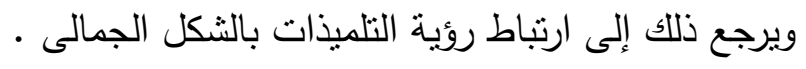

الثكل (ع) يوضح الفروق في معاملات الجودة للتصاميم من حيث تقديرات التلميذات:

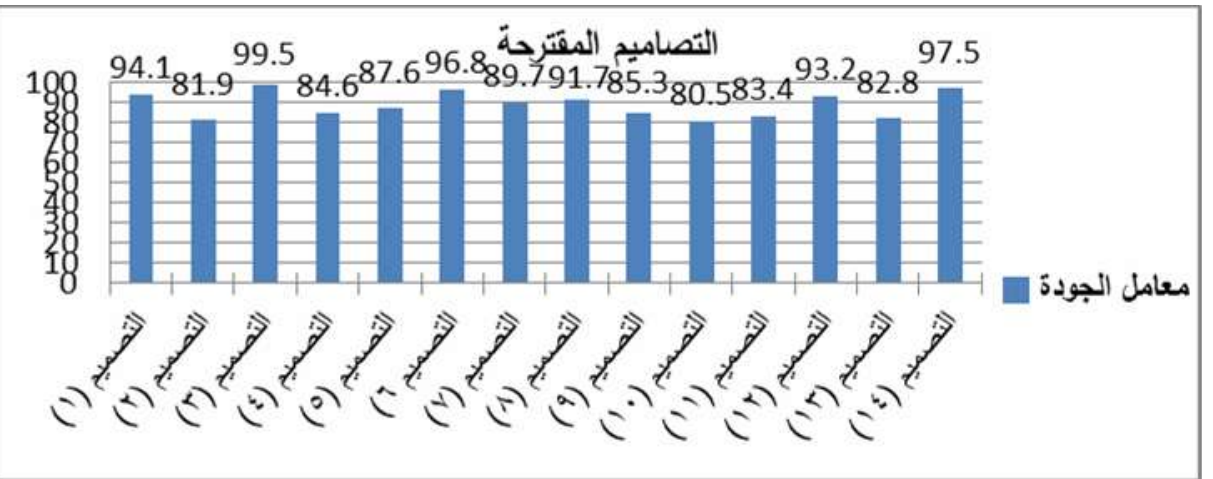

شكل (ع) معاملات الجودة للتصاميم المقترحة محل الدراسة من حيث تقديرات التلميذات

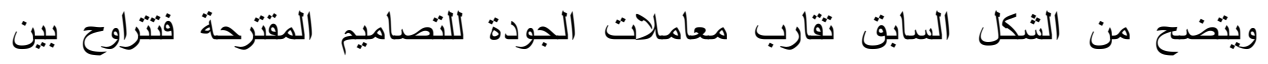

$$
\text { \% 99.0 } 99
$$

ولإيجاد الفروق بين متوسطات تقديرات التلميذات تم حساب تحليل التباين ثثائي الاتجاه

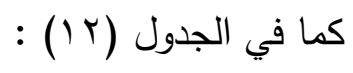


جدول(Y I ) نتائج تحليل التباين ثنائي الاتجاه بين محاور الاستبانة الرابعة والتصاميم المقترحة

\begin{tabular}{|c|c|c|c|c|c|c|}
\hline F crit & $\mathrm{P}$-value & $F$ & MS & DS & SS & مصدر التباين \\
\hline Y.АTYI & ..YIV & T.ITr & ry.0Yl & $\varepsilon$ & $1 \leq 0 . .4$ & الدحاور \\
\hline$r . v 1.9$ & $\ldots \mu_{1}$ & ह.ाTा & $1.9 . .4$ & 0 & o7r... & التصا \\
\hline
\end{tabular}

يتضح منالجدول وجود اختلاف معنوي بين منوسطات تقديرات التلميذات لمحاورالتقييم عند مستوى معنويةه ...بينمالايوجد اختلاف معنوي بين متوسطات تقديرات التلميذات للتصاميم عند مستوى معنوية ه ... ، وهو ما يؤكد تحقق الفرض الرابع ، وبذلك نكون أجبناعلى التساؤل

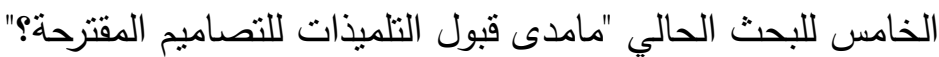
نتائج الفرض الخامس : " توجد فروق دالة إحصائيا بين التصاميم المقترحة للزى المدرسي في كئ ضوء منوسطات التقييم ككل "

\begin{tabular}{|c|c|c|c|c|c|c|c|c|c|c|c|c|c|c|}
\hline$\frac{\sqrt{3}}{\frac{3}{2}}$ & 司 & $\frac{\sqrt{3}}{2}$ & $\frac{\overline{9}}{\underline{3}}$ & $\frac{\text { 可 }}{\text { 景 }}$ & $\frac{\sqrt{3}}{\hat{\sigma}}$ & $\frac{3}{3}$ & $\frac{\text { 可 }}{\text { 是 }}$ & $\frac{\text { 可 }}{\text { 景 }}$ & 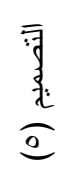 & 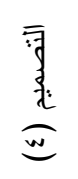 & $\frac{3}{3}$ & $\frac{\text { 可 }}{\text { 景 }}$ & $\frac{\text { 可 }}{\text { 录 }}$ & عينة|لي \\
\hline จ४. & NI.r & $9 \leq .$, & Ar & $\begin{array}{c}A . \\
+\end{array}$ & $\lambda \varepsilon .0$ & 91.9 & M.T & 98.9 & 10.1 & Ar.r & 99 & $\wedge$ & 97.7 & - المتخصين \\
\hline $9 \wedge .1$ & Ar.r & १ะ..। & $\Delta r .4$ & $\begin{array}{c}\wedge . \\
r\end{array}$ & AV.r & ar & 91.9 & av.r & $\wedge 9.9$ & 10.9 & 9 9А. & N.r & 90.0 & - المنتجين \\
\hline $99 . \%$ & $10 . \leqslant$ & $90 . \varepsilon$ & Av. & $\begin{array}{l}\text { Al. } \\
9\end{array}$ & 9. & $9 \leqslant .0$ & GY. & 91.7 & $9 . .7$ & $\wedge \wedge .9$ & $99 . \wedge$ & Ar.q & av & - الأمهات \\
\hline 9 9..० & $\Lambda$ Ar.A & ar.r & $\Delta r . \varepsilon$ & $\begin{array}{l}\text { A. } \\
0\end{array}$ & 10.r & $91 . \mathrm{V}$ & A9.V & 97.1 & Av. T & $\wedge \varepsilon .4$ & 99.0 & 11.9 & 9๕.. & - التلميذات \\
\hline $9 \wedge$ & Ar.q & $9 \varepsilon .$. & $\wedge \varepsilon$ & ᄉ. & ᄉ $4 . \wedge$ & $9 r . A$ & $9 . .7$ & qY.V & $\wedge 1.0$ & 10.v & $99 . r$ & ㅅ.. & 90.1 & معامل الجودة \\
\hline الثانى & عشر & س الخام & عشر الحادي & عشر & التاسع & س الساد & السابع & الثالث & الثامن & العاثر & الأول & عشر الثالث & الرابع & التزتيب \\
\hline
\end{tabular}

يتضح من الجدول إجماع عينات البحث على قبول التصاميم المقترحة بهدف إطالة فترة

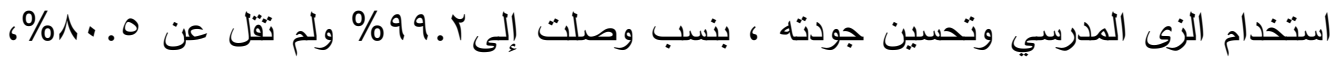

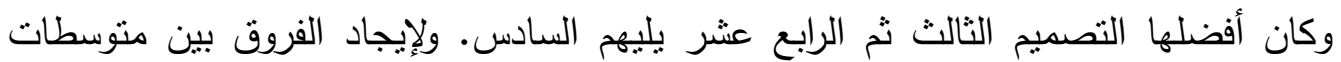
تقييم عينات البحث تم حساب تحليل التباين أحادى الاتجاه كالاتى :

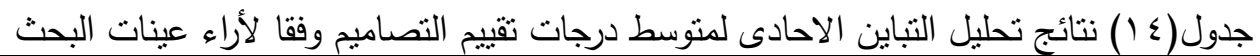

\begin{tabular}{|c|c|c|c|c|c|}
\hline الدلالة & قيـــة "ف" & درجات الحرية & متوسط المربعات & مجموع المربعات & مصدر التباين \\
\hline \multirow[t]{2}{*}{$\ldots 1$} & \multirow[t]{2}{*}{ T0.TY } & 19 & $O V \varepsilon .11 T$ & $1.9 \cdot 1.1 \leq 7$ & بين المجموعات \\
\hline & & rq. & 17.117 & $\sum 19 . .1 . r$ & داخل المجموعات \\
\hline & & rvq & & $10.91 . r \leq 9$ & المجموع \\
\hline
\end{tabular}




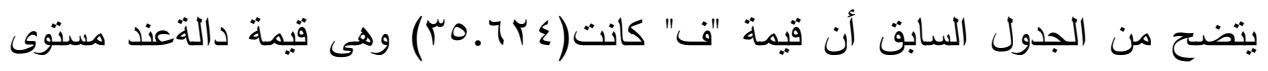
(1 ( . •)ممايدل على وجود فروق بين التصاميم المقترحة ويؤكد تحقق الفرض الخامس نتائج الفرض السادس : " إمكانية إعداد ملف فني لإنتاج أمثل التصاميم المقترحة وصلاحيتها

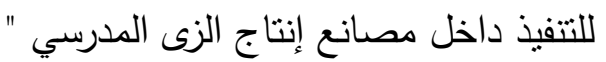
تم اختيارأفضل ثلاث تصاميم لإعداد ملف فني لهم وتتفيذهم بمصانع الزى المدرسى كالاتى:

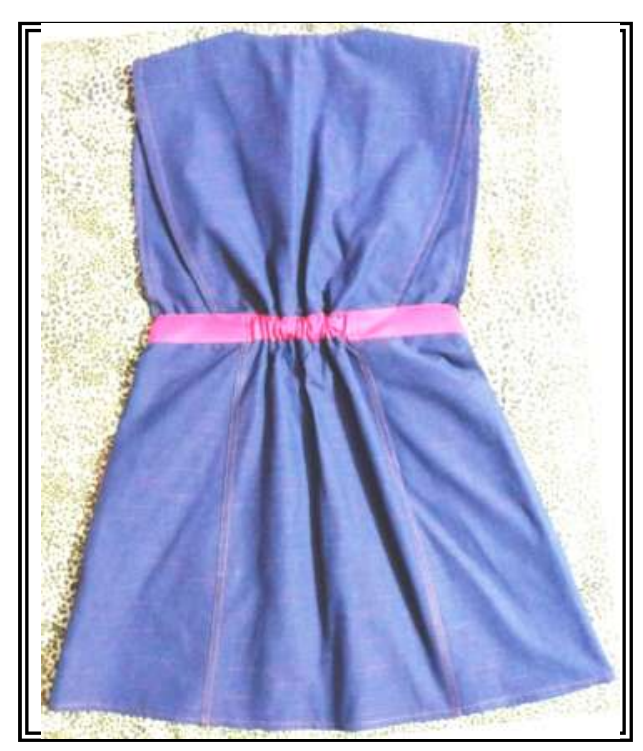

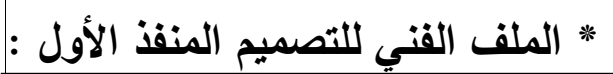

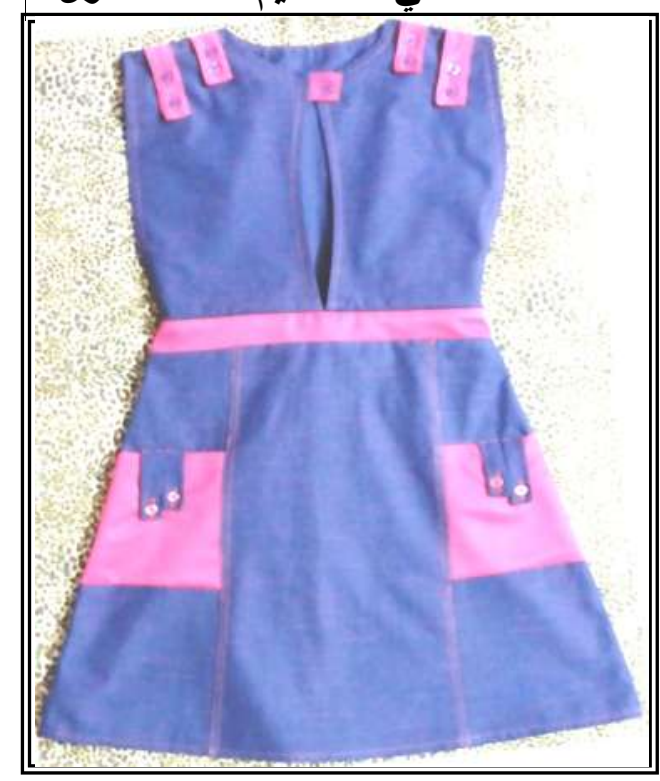

صورة (1) العينة المنفذة الأولى " منظر أمامي ، خلفي " 


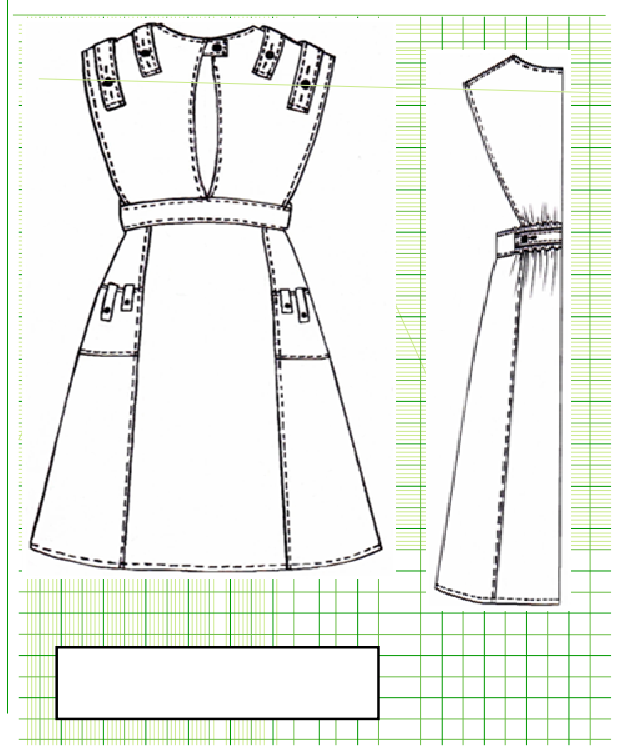

شكل(0) البناء الهندسي لتصميم العينة المنفذةالأولى

\begin{tabular}{|c|c|c|c|}
\hline \multicolumn{2}{|l|}{ Designer : } & \multirow{2}{*}{\multicolumn{2}{|c|}{ 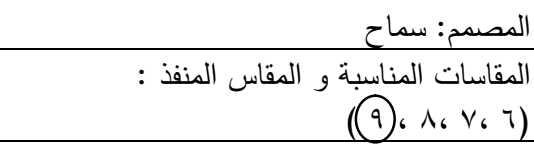 }} \\
\hline \multicolumn{2}{|l|}{ Sizes : } & & \\
\hline \multicolumn{2}{|l|}{ Season: } & \multicolumn{2}{|c|}{ الموسم : صيف/نشتاء } \\
\hline \multicolumn{2}{|l|}{ Description: } & \multicolumn{2}{|c|}{ التوصيف : زي مدرسى "دريل" } \\
\hline \multicolumn{4}{|l|}{ Fabric : } \\
\hline \multicolumn{2}{|c|}{ مخلوط (قطن/ بوليستر) } & \multicolumn{2}{|r|}{ 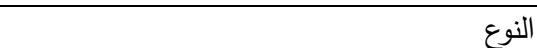 } \\
\hline \multicolumn{2}{|c|}{ سادة 1// } & \multicolumn{2}{|r|}{ التزكيب النسجي } \\
\hline \multicolumn{2}{|c|}{ كحلى × بطيخى } & \multicolumn{2}{|r|}{ اللون } \\
\hline \multicolumn{4}{|c|}{ Accessories: : "المكملات "الخامات المساعدة } \\
\hline أستيك & أزرار & خيط & النوع \\
\hline بوليستر & بلاستيك & بوليستر & 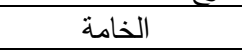 \\
\hline ס סسم & متوسط & $r / \varepsilon r$ & الحجم \\
\hline أبيض & كحلى 'بطيخى & كحلى 'بطيخى & اللون \\
\hline الكمر & لوكسات & الحباكات & الموضع \\
\hline
\end{tabular}

جدول(0) مواصفات العينة المنفذة الأولى 
جدول (17 ) مراحل تشغيل "تجميع" العينة المنفذة الأولى

\begin{tabular}{|c|c|c|c|c|c|c|c|}
\hline نوع الملحق & الخيوط & عدد & رقم & الماكينة & توصبف المرحلة & المرحلة & r \\
\hline تعريش & Tr & 1 & $\overline{r \cdot 1}$ & سنجر & مع اليمنى واليسرى طبقتي الصدراً لشكلها فيطانة للجهتين التصيم & تركيب بطانة & 1 \\
\hline دواسة شيمة & $r$ & r & $r \cdot 1$ & سنجر & جزئى الصدر باستخد وعرض دواس إبرة مزدوجة حواف & بنط الصدر & r \\
\hline تعريش & $r$ & 1 & $r \cdot 1$ & سنجر & حياكة طبقتي اللوكسات معاً مع تعريش الزيادات & رسم لوكسات & $r$ \\
\hline تعريش & $r$ & $r$ & $r \cdot 1$ & سنجر & تركيب لوكسات الكتق بين طبقتى الظهر & تركيب لوكسات & $\varepsilon$ \\
\hline تعريش & $r$ & 1 & $r \cdot 1$ & سنجر & لشكلها في التصميم مع تعريش زيادات الخياطة النبة & تركيب بطانة & 0 \\
\hline دواسة شيمة & $r$ & $r$ & $r \cdot 1$ & سنجر & قصل الظهر باستخدام إبرة مزدوجة على حواف & بنط الظهر & 7 \\
\hline تعريش & r & 1 & $r \cdot 1$ & سنجر & الزيادات طباكة طنتي اللوكسات معاً مع تعريش & رسم لوكسات & 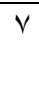 \\
\hline دواسة شيمة & r & 1 & $r \cdot 1$ & سنجر & لمكانها في النصميب على جزء الجونلة تبعاً & تركيب الجيب & $\wedge$ \\
\hline دواسة شيمة & $r$ & 1 & $r \cdot 1$ & 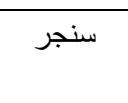 & 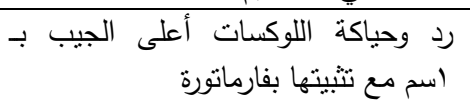 & تركيب لوكسات & 9 \\
\hline دواسة شيمة & $r$ & $r$ & $r \cdot 1$ & سنجر & 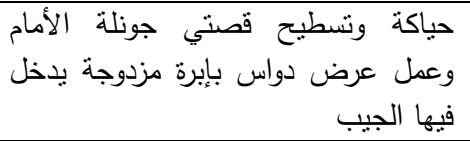 & تجميع قتصنى الأمام & ! \\
\hline دواسة شيمة & $r$ & 1 & $r \cdot 1$ & سنجر & 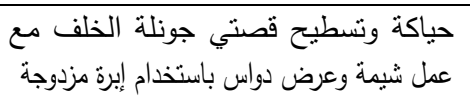 & تجميع قصنى الخلف & $\begin{array}{l}1 \\
1\end{array}$ \\
\hline- & 0 & $r$ & 017 & فأوفرلوكه & وحتى الذيل خطي الجناب معاً بدءاً من الوسط & سد الجناب & $\begin{array}{l} \\
1 \\
r\end{array}$ \\
\hline دواسة شيمة & $r$ & $r$ & $r .1$ & سنجر & 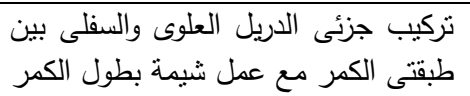 & تركيب الكمر & 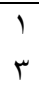 \\
\hline تعريش & $r$ & 1 & $r \cdot 1$ & سنجر & الزيادات طبقتي اللوكسات معاً مع تعريش & رسم لوكسات & 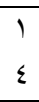 \\
\hline- & - & - & - & 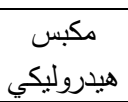 & تركيب لوكسات الكمر وذللك بكبسونة واحتبيتها بالخلف & تركيب لوكسات & $\begin{array}{l}1 \\
0\end{array}$ \\
\hline دواسة شيمة & $r$ & $r$ & $r .1$ & سنجر & 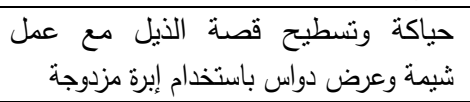 & تجميع قصة & $\begin{array}{l}1 \\
1\end{array}$ \\
\hline- & - & - & - & هيدروليكي & 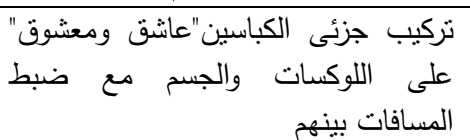 & تزكيب كباسين & $\begin{array}{l}1 \\
v\end{array}$ \\
\hline
\end{tabular}




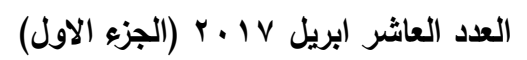

المجلة العلمية لكلية التربية النوعية
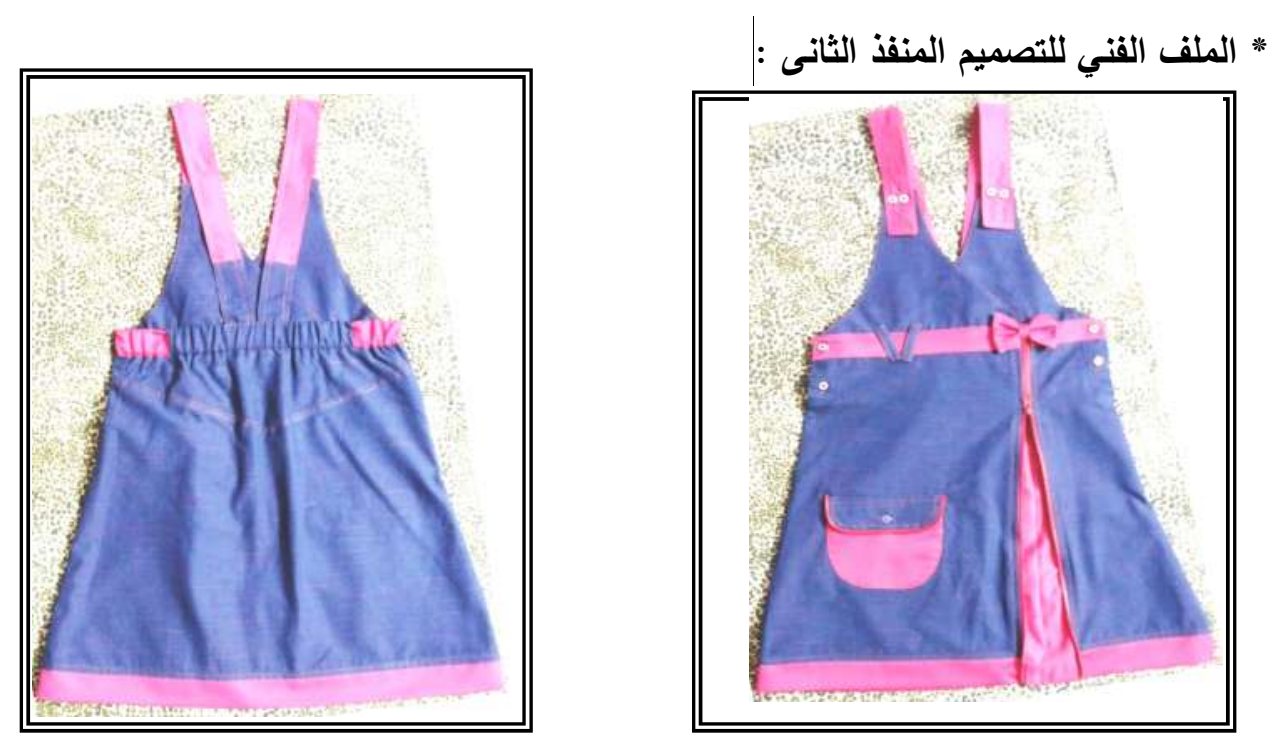

صورة (ץ) العينة المنفةة الثانية " منظر أمامي ، خلفي "

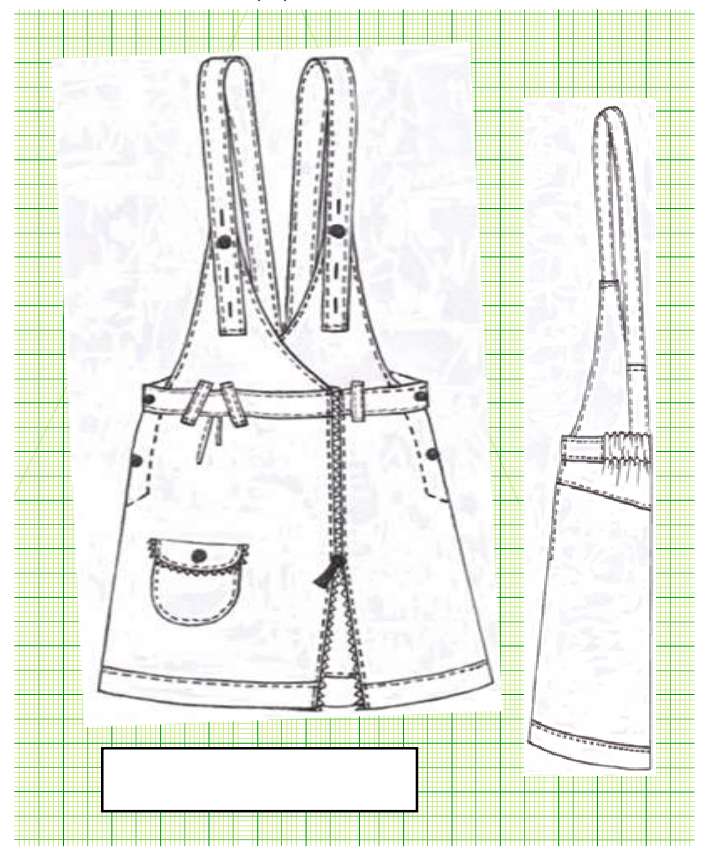

شكل(7)|البناء الهندسي للتصميم المسطح للعينة الثانية

\begin{tabular}{|c|c|}
\hline Designer : & المصمح: سماح \\
\hline Sizes : & 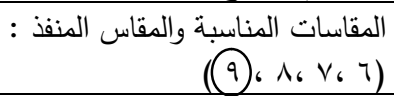 \\
\hline Season: & الموسم : صيف/شتاء \\
\hline Description: & التوصيف : زي مدرسى "دريل" \\
\hline
\end{tabular}




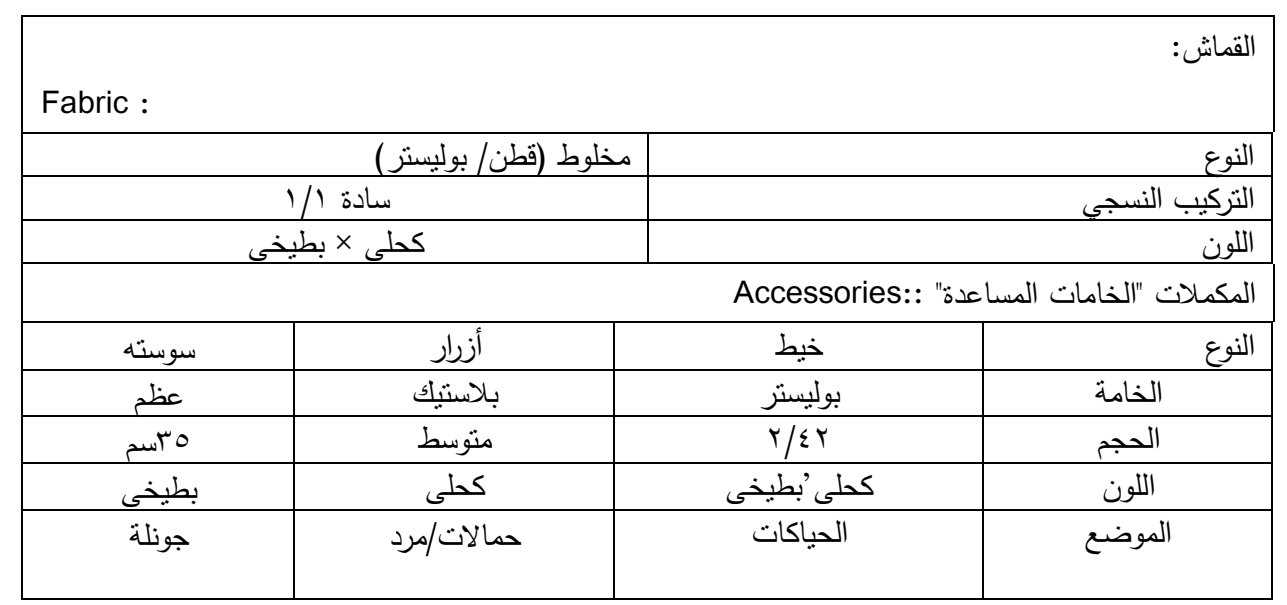

جدول (IV) مواصفات العينة المنفذة الثانية

جدول (1) مراحل تثنغيل "تجميع" العينة المنفذة الثانية

\begin{tabular}{|c|c|c|c|c|c|c|c|}
\hline نوع الملحق & الخيوط & | عداد & رق & نوع الماكينة & توصيف المرحلة & المرحلة & م \\
\hline تعريش & $r$ & 1 & $r .1$ & سنجر & تعريش زيادة الصدر والبطانة للجنتين اليمنى & بطانة & 1 \\
\hline دواسة شيمة & $r$ & $r$ & $r .1$ & سنجر & جزئى الصدر باستخدام إبرة مزدوجة دواس عواف & بنط الصدر & $r$ \\
\hline | تعريش & r & 1 & $r .1$ & سنجر & حياكة طبقتي الحمالات معاً مع تعريش & 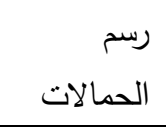 & $r$ \\
\hline دواس شيمة & $r$ & $r$ & $r .1$ & سنجر & 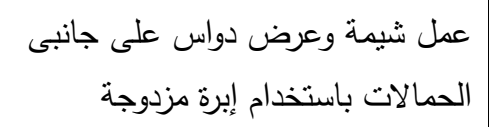 & بنط & $\varepsilon$ \\
\hline دواسة شيمة & $r$ & r & $r .1$ & سنجر & 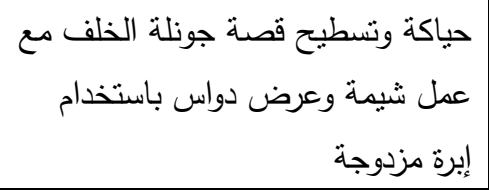 & قجميع & 0 \\
\hline دواسة شيمة & r & r & $r .1$ & سنجر & قد ردم ضاغط بسكة أستيك كمر الخلف باستخدام & تركيب & 7 \\
\hline دواسة شيمة & $r$ & r & $r .1$ & سنجر & الكركيب جزئى الدريل العلوى والسفلى بين & ن تركيب كمر & v \\
\hline
\end{tabular}




\begin{tabular}{|c|c|c|c|c|c|c|c|}
\hline | - ت تعريش & $r$ & 1 & $r .1$ & سنجر & |الزياداتة طبقتي اللوكسات معاً مع نعريش & لوكسمات & $\wedge$ \\
\hline 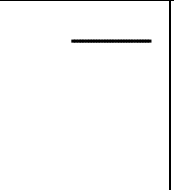 & $r$ & 1 & $r .1$ & سنجر & 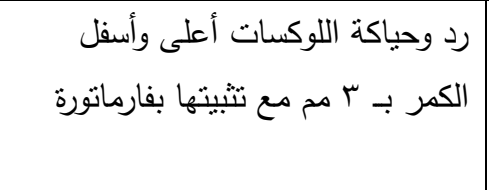 & تركيب & 9 \\
\hline دواسة شيمة & $r$ & $r$ & $r .1$ & سنجر & 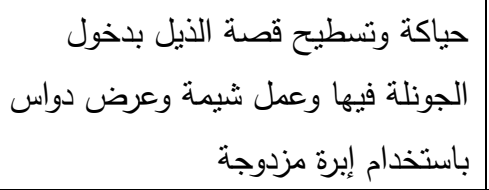 & تجميع الذيل & 1. \\
\hline دواسة شيمة & $r$ & $r$ & $r .1$ & سنجر & | وعمل عرض دواس وتسطيح قصة جونلة الأمام & تصميع & 11 \\
\hline دواسة شيمة & $r$ & 1 & $r .1$ & سنجر & الدريل تبعاً لدكانه في التصميم الجيب النفلى من & تركيب & Ir \\
\hline تعريش & $r$ & 1 & $r .1$ & سنجر & | حياكة طبقتي القلاب معاً مع تعريش & ر بل الجيب & 14 \\
\hline دواسة شيمة & $r$ & $r$ & $r .1$ & سنجر & 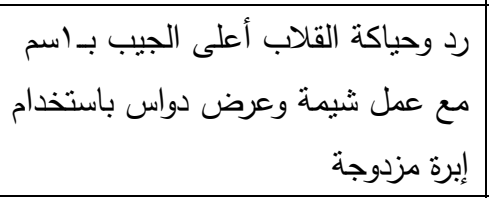 & تركيب & $1 \varepsilon$ \\
\hline 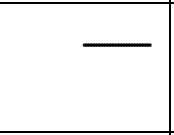 & 0 & $r$ & 017 & أوفرلوك هفتلة & 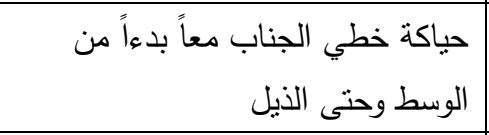 & سد الجناب & 10 \\
\hline & $r$ & $r$ & $\Gamma .1$ & سنجر & 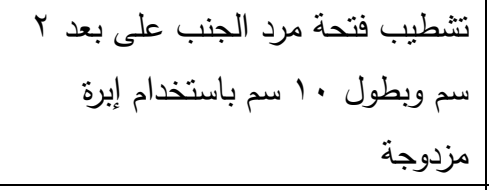 & تشطيب & 17 \\
\hline - & r & 1 & 1.1 & عراوى & | عمل العراوى على كل من الحمالات & عمل ع العراوى & IV \\
\hline- & $r$ & 1 & 1.1 & الأزرار & |نركيب الأزرار على نفس مسنوى أماكن العراوى & 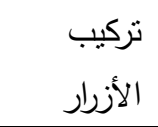 & 11 \\
\hline
\end{tabular}


العدد العاشر ابريل VI P. (الجزء الاول)

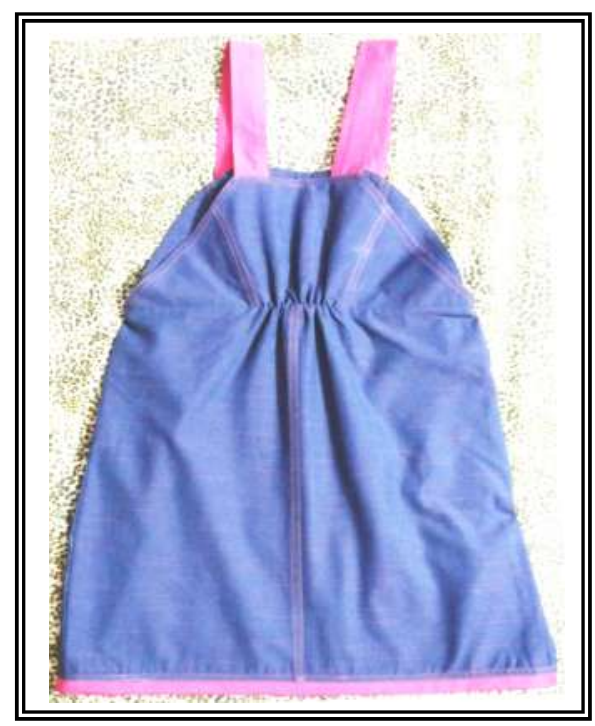

المجلة العلمية لكلية التربية النوعية

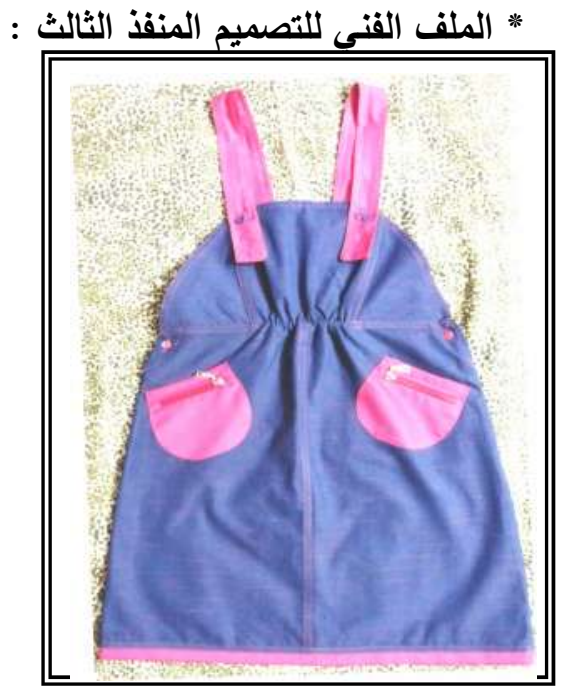

صورة (Y) العينة المنفذة الثالثة " منظر أمامي ، خلفي

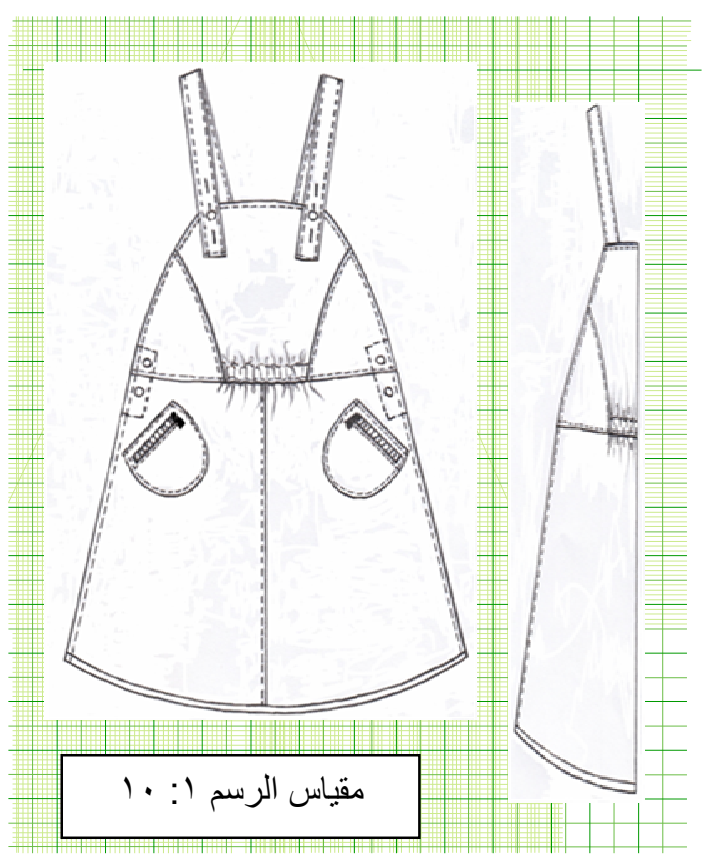

شكل(†) البناء الهندسي للتصميم المسطح للعينة الثالثة 


\begin{tabular}{|c|c|c|c|}
\hline \multicolumn{2}{|l|}{ Designer : } & \multicolumn{2}{|r|}{ المصمم: سماح } \\
\hline Sizes : & & \multicolumn{2}{|c|}{ 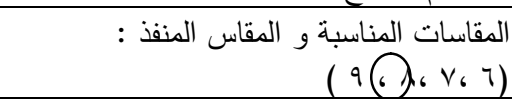 } \\
\hline \multicolumn{2}{|l|}{ Season: } & \multicolumn{2}{|c|}{ الموسم : صبف/شتاء } \\
\hline \multicolumn{2}{|l|}{ Description: } & \multicolumn{2}{|c|}{ التوصيف : زي مدرسى "دريل" } \\
\hline \multicolumn{2}{|c|}{ Fabric : } & \multicolumn{2}{|c|}{ القماش: } \\
\hline \multicolumn{2}{|c|}{ مخلوط (قطن/ بوليستر) } & \multicolumn{2}{|r|}{ النوع } \\
\hline \multicolumn{2}{|c|}{ 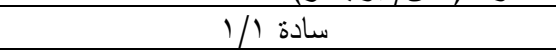 } & \multicolumn{2}{|r|}{ التزكيب النسجي } \\
\hline \multicolumn{2}{|c|}{ كحلى × بطيخى } & & اللون \\
\hline \multicolumn{4}{|c|}{ Accessories:: "المكملات "الخامات المساعدة" } \\
\hline سوسته & أزرار & خيط & 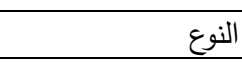 \\
\hline عظم & بلاستيك & بوليستر & 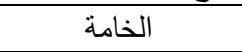 \\
\hline 9 - 19م & متوسط & $r / \leqslant r$ & الحجم \\
\hline بطيخى & كلى 'بطيخى & كلى 'بطيخى & 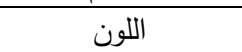 \\
\hline الجيوب & حمالات/مرد & 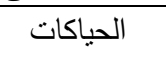 & الموضع \\
\hline
\end{tabular}

جدول(Y (Y ) مواصفات العينة المنفذة الثالثة

جدول (· r) مراحل تثغيل "تجميع" العينة المنفذة الثالثة

\begin{tabular}{|c|c|c|c|c|c|c|c|}
\hline الملدق & الخيوط & عداد & ر الغرزم & نوع الماكينة & توصيف المرحلة & المرحة & p \\
\hline ش د دواسة & $\Gamma$ & Tr & $r .1$ & سنجر & 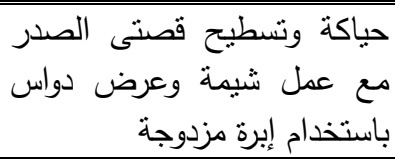 & تصنيع & 1 \\
\hline | ت نعريش & $r$ & 1 & $r .1$ & سنجر & تعريش الزيادات الحمالات معاُ مع & الحمالات & 2 \\
\hline 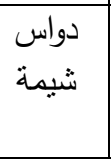 & $r$ & $r$ & $r \cdot 1$ & سنجر & عزدمل شيمة وعرض الحمالات باستخدام إبرة على & الحمالات & 3 \\
\hline | ت تعريش & $r$ & 1 & $r .1$ & سنجر & معا تبعاً لشبقى الصديا فيى التصديم والبطانة & بطانة & 4 \\
\hline 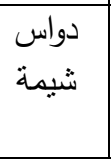 & $r$ & $r$ & $r .1$ & سنجر & عماف شيمة وعرض الصدر دواستخدام على & بنط الصدر & 5 \\
\hline شيمة & $r$ & $r$ & $r \cdot 1$ & سنجر & 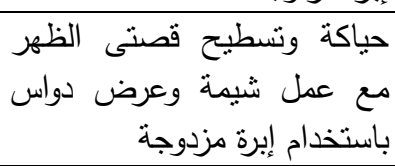 & تجنيع & 6 \\
\hline ت ن سكيش & $r$ & 1 & $r \cdot 1$ & سنجر & معاعلى أن يبقى الظهر و طينهر طرفى & بطانة الظهر & 7 \\
\hline
\end{tabular}




\begin{tabular}{|c|c|c|c|c|c|c|c|}
\hline & & & & & الحمالات مع تعريش الزيادات & & \\
\hline شواس & $r$ & $r$ & $r \cdot 1$ & سنجر & 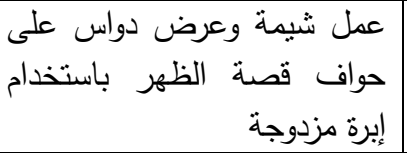 & بنط الظهر & 8 \\
\hline شواسةة & $r$ & $r$ & $r \cdot 1$ & سنجر & 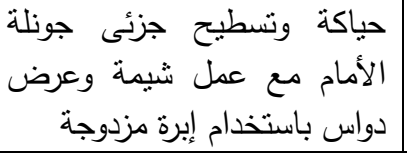 & تجميع جزئى الجونلة & 9 \\
\hline سوستة & $r$ & 1 & $r \cdot 1$ & سنجر & 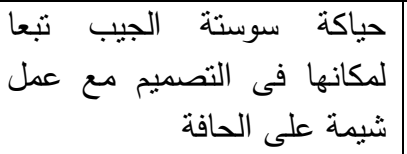 & سوكيبة & 10 \\
\hline شواسة & r & 1 & $r \cdot 1$ & سنجر & 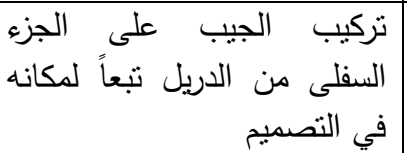 & تركيب & 11 \\
\hline & $r$ & $r$ & $r \cdot 1$ & سنجر & 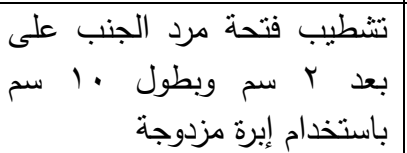 & نشطيب مرد & 12 \\
\hline & 0 & $r$ & 017 & أوفرلوك هفتلة & من الوسط وحتى الذيل & سد الجناب & 13 \\
\hline | الأسنتك & $r$ & $r$ & $r \cdot 1$ & سنجر & خارجية & تجميع جزئى الأمام & 14 \\
\hline | الأستيك & $r$ & r & $r \cdot 1$ & سنجر & خارجية & تجيل جزئى الخلف & 15 \\
\hline & r & 1 & $\Gamma \cdot 1$ & سنجر & تشطيب ذيل الدريل ببييه & تركيب بييه & 16 \\
\hline - & r & 1 & $1 \cdot 1$ & عراوى & 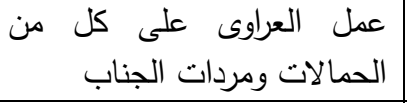 & العراوى عمل & iv \\
\hline 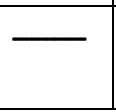 & r & 1 & 1.1 & الأزرار & 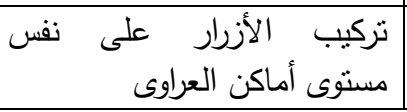 & الأزرار & 11 \\
\hline
\end{tabular}

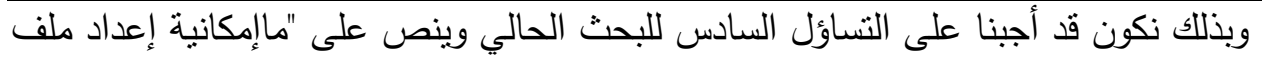

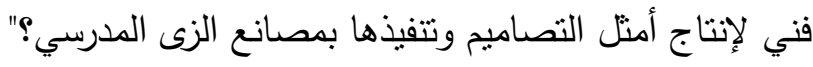

Recommendation : التوصيات

1-الاستفادة من نتائج البحث في وضع مواصفة قياسية محددة لتصميم الزى المدرسي

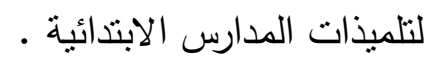
ץ-إجراء المزيد من الدراسات حول تتفيذ الزى المدرسي والتقنيات المتلى لحياكته . 


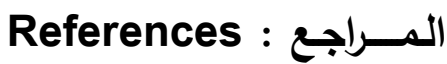

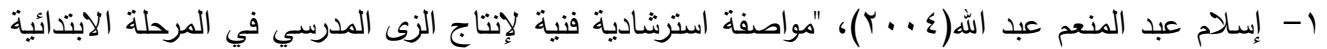

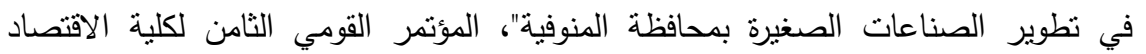

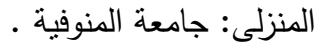

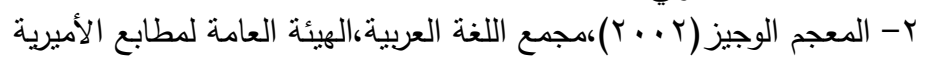

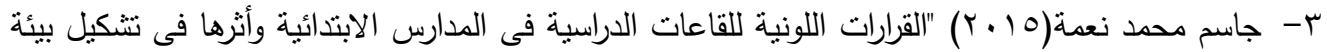

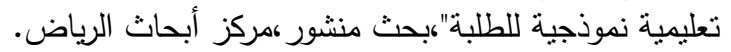

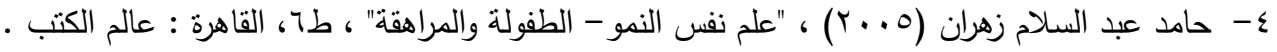

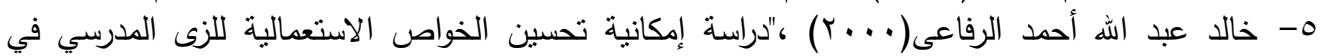

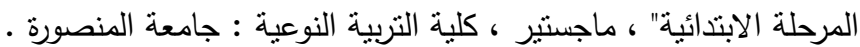

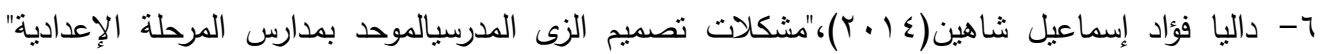

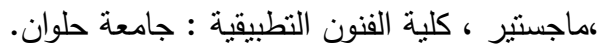

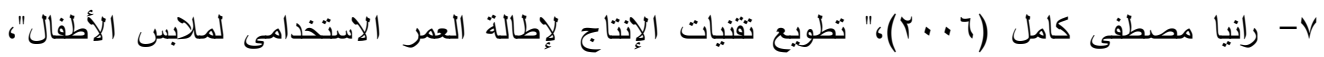

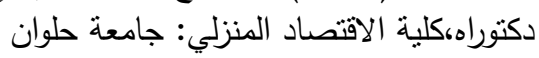

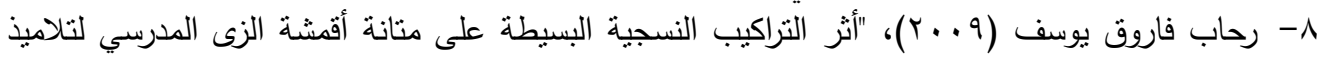

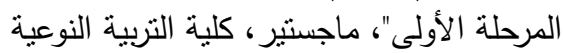

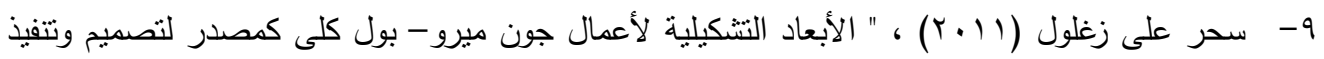

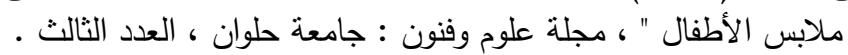

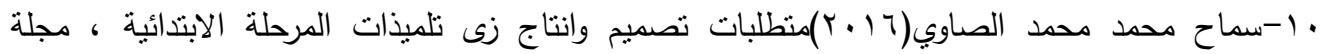

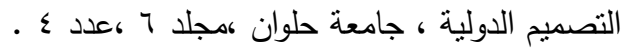

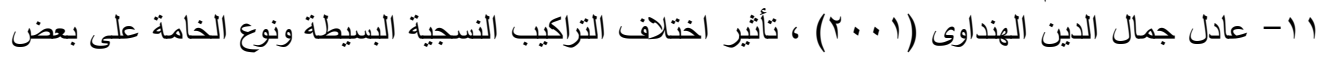

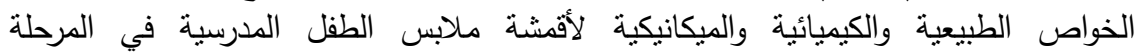

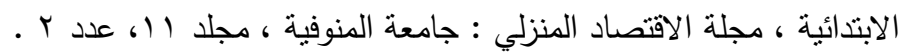

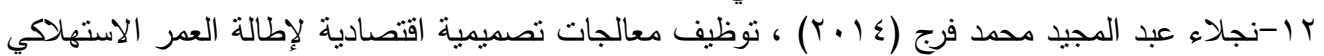

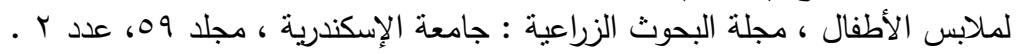

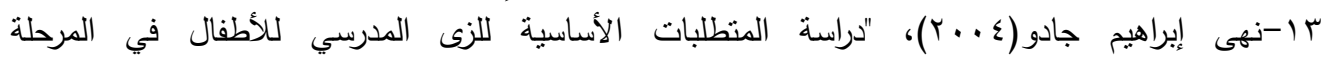

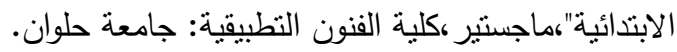

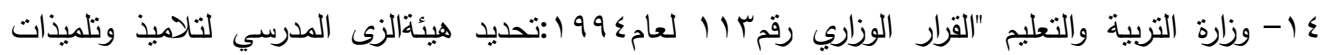

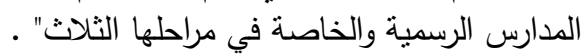

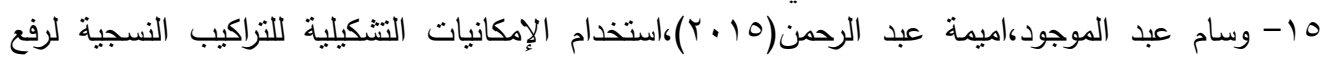

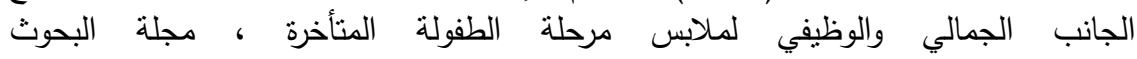

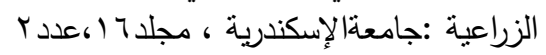

16-Craik Jennifer (2002): Uniforms Exposed From Conformity To Transgression.

17- Mary Wolfe (1998): Fashion - the good heart, Wilcox company, INC, U.S.A.

18-Moen.R.\& Nolant.t (1991): Improving quality through planned experimentation, new York, 1991.

19- Patrick john (1995): Fashion design illustration children, Ireland. 21 - www. thefreedictionary.com/drill+clothes / 